
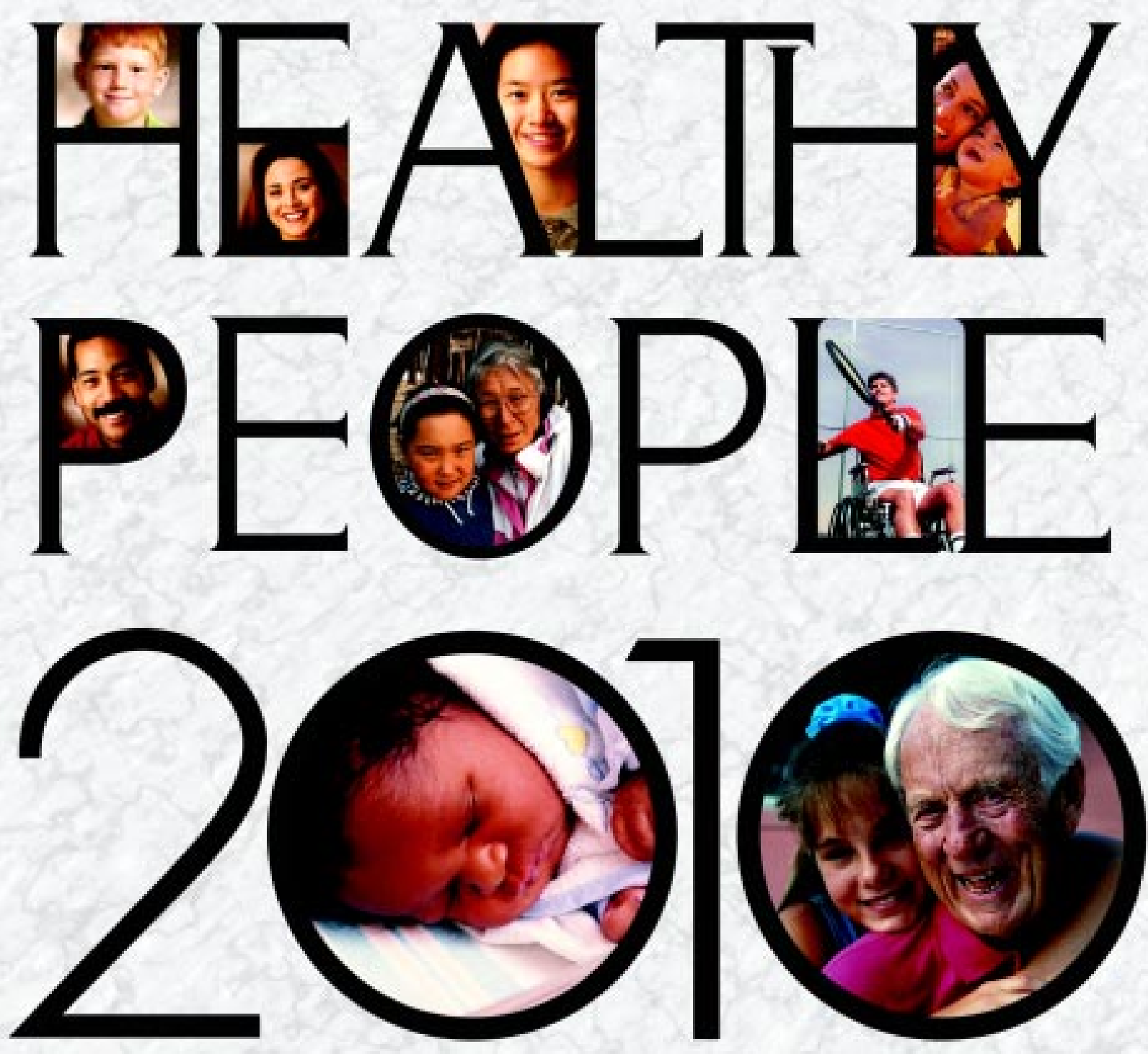

Understanding and Improving Health 


\section{Note to Readers}

This edition of Healthy People 2010: Understanding and Improving Health supersedes the January 2000 Conference Edition. It includes updated data. In some cases, these updates have resulted in revised baselines and targets for objectives and in revisions to the text. For further explanation of differences between the editions, please refer to the Reader's Guide in volume I of Healthy People 2010, 2nd ed.

For detailed information on objectives and data systems, see the companion document Tracking Healthy People 2010.

To access the Healthy People 2010 documents online, visit http://www.health.gov/healthypeople/. For more information visit this Web site or call 1-800-367-4725.

\section{Suggested Citation}

U.S. Department of Health and Human Services. Healthy People 2010: Understanding and Improving Health. 2nd ed. Washington, DC: U.S. Government Printing Office, November 2000 .

For sale by the U.S. Government Printing Office, Superintendent of Documents, Washington, DC 20402-9382, Stock Number 017-001-001-00-550-9. 


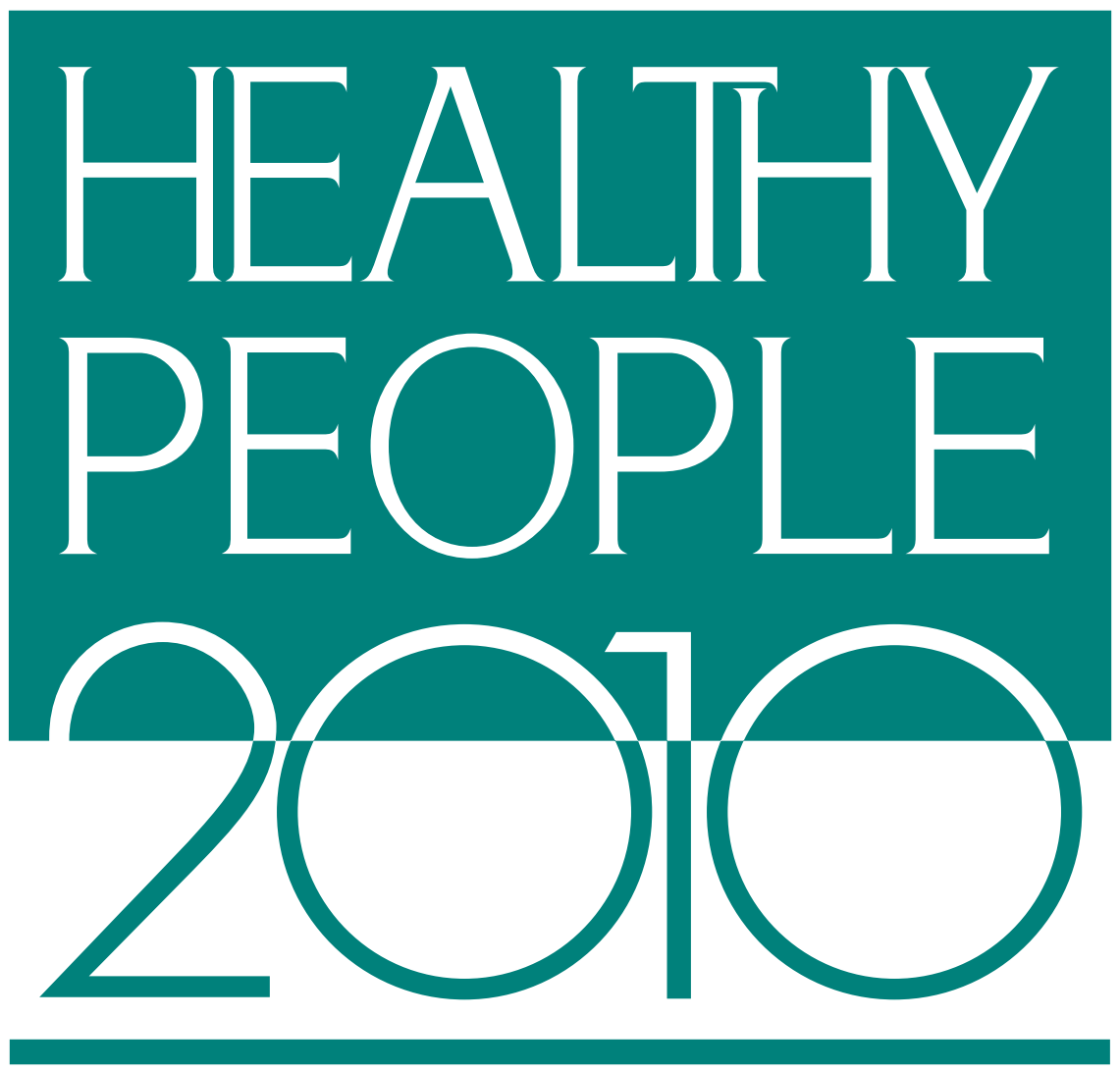

\section{Understanding and Improving Health}

U.S. Department of Health and Human Services November 2000 



\section{Message from the Secretary}

Healthy People 2010 provides our Nation with the wide range of public health opportunities that exist in the first decade of the 21 st century. With 467 objectives in 28 focus areas, Healthy People 2010 will be a tremendously valuable asset to health planners, medical practitioners, educators, elected officials, and all of us who work to improve health. Healthy People 2010 reflects the very best in public health planning - it is comprehensive, it was created by a broad coalition of experts from many sectors, it has been designed to measure progress over time, and, most important, it clearly lays out a series of objectives to bring better health to all people in this country.

Achieving the vision of "Healthy People in Healthy Communities" represents an opportunity for individuals to make healthy lifestyle choices for themselves and their families. It challenges clinicians to put prevention into their practices. It requires communities and businesses to support healthpromoting policies in schools, worksites, and other settings. It calls for scientists to pursue new research. Above all, it demands that all of us work together, using both traditional and innovative approaches, to help the American public achieve the 10-year targets defined by Healthy People 2010.

The 20th century brought remarkable and unprecedented improvements in the lives of the people of the United States. We saw the infant mortality rate plummet and life expectancy increase by 30 years. While we recognize that most of the advances came from prevention efforts, we also saw almost unimaginable improvements in medical technologies and health care. The challenge for the $21 \mathrm{st}$ century is twofold. First, we must ensure that this rate of advancement continues unabated. Second, we must make certain that all Americans benefit from advancements in quality of life, regardless of their age, race, ethnicity, gender, sexual orientation, disability status, income, educational level, or geographic location. These challenges are substantial, but with the objectives defined by Healthy People 2010, they are achievable.

I wholeheartedly commend Healthy People 2010, and I challenge all of us to work together to achieve its ambitious and important vision.

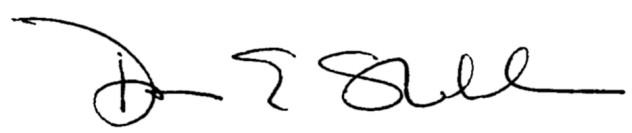

Donna E. Shalala

Secretary of Health and Human Services 



\section{Foreword}

We have witnessed a great deal of progress in public health and medicine since our Nation first embarked on the national planning process for the Healthy People initiative. The process began in 1979 with Healthy People: The Surgeon General's Report on Health Promotion and Disease Prevention, which was followed in 1990 by Healthy People 2000. Healthy People 2010 represents the third time that the U.S. Department of Health and Human Services (HHS) has developed 10-year health objectives for the Nation.

Healthy People 2010 reflects the scientific advances that have taken place over the past 20 years in preventive medicine, disease surveillance, vaccine and therapeutic development, and information technology. It also mirrors the changing demographics of our country, the changes that have taken place in health care, and the growing impact of global forces on our national health status.

Healthy People 2010 incorporates input from a broad cross-section of people. Scientific experts from many Federal agencies took the lead in developing the focus areas and objectives. The Secretary's Council on National Health Promotion and Disease Prevention Objectives for 2010 and the Healthy People Steering Committee provided guidance to steer the process. The HHS Office of Public Health and Science, particularly the Office of Disease Prevention and Health Promotion, expertly managed the process. But perhaps most important to the success of this effort was the overwhelming and enthusiastic contribution made by the Healthy People Consortium and the public. We received more than 11,000 comments from people in every State by fax, Internet, letter, and in person through several public meetings.

The knowledge, commitment, and collaboration of these groups have combined to produce national health objectives that are even more comprehensive than their predecessors. There are 467 objectives in 28 focus areas, making Healthy People 2010 an encyclopedic compilation of health improvement opportunities for the next decade. Building on two decades of success in Healthy People initiatives, Healthy People 2010 is poised to address the concerns of the 21 st century. Two major goals reflect the Nation's changing demographics. The first goal, which addresses the fact that we are growing older as a Nation, is to increase the quality and years of healthy life. The second goal, which addresses the diversity of our population, is to eliminate health disparities.

And, for the first time, a set of Leading Health Indicators will help individuals and communities target the actions to improve health. The Leading Health Indicators also will help communities track the success of these actions.

I sincerely appreciate the number of people, institutions, and organizations that have worked together to create this important document. But our journey has just begun. I encourage you to stay the course as we pursue the vision of Healthy People 2010 to create tomorrow's healthier people today.

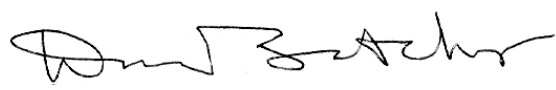

David Satcher, M.D., Ph.D. Assistant Secretary for Health and Surgeon General 



\section{Acknowledgments}

Healthy People 2010: Understanding and Improving Health is part of the Healthy People 2010 initiative sponsored by the U.S. Department of Health and Human Services. Leadership and direction were provided by David Satcher and Nicole Lurie. Development of Healthy People 2010 has been coordinated by the Office of Disease Prevention and Health Promotion under the leadership of Claude Earl Fox, Susanne A. Stoiber, Linda D. Meyers, and Randolph F. Wykoff.

Principal responsibility for Healthy People 2010: Understanding and Improving Health was carried out by Mark S. Smolinski. Critical editorial and technical support were provided by Carter Blakey, Mary Jo Deering, Matthew Guidry, Deborah R. Maiese, Linda D. Meyers, Janice T. Radak, Kelly H. Woodward, and Randolph F. Wykoff. Special thanks are due to David Atkins, Linda A. Bailey, Ron Davis, Kate-Louise Gottfried, James Harrell, J. Michael McGinnis, Kevin Patrick, Scott C. Ratzan, Dirk Ruwaard, Susanne A. Stoiber, and Tom Vischi.

Statistical advice and data development were provided by staff of the Division of Health Promotion Statistics of the National Center for Health Statistics, Centers for Disease Control and Prevention, which included Jeanette Guyton-Krishnan, Elizabeth Jackson, Richard J. Klein, Cheryl Rose, Colleen Ryan, J. Fred Seitz, Thomas Socey, Kathleen Turczyn, Jennie Wald, and Jean Williams, under the leadership of Diane K. Wagener.

Research of the literature and other resources was provided by preventive medicine residents and medical students: Madhavi Battineni, Joy L. Bottoms, Wayne Brandes, Dominic Cheung Chow, Penny Shelton-Hoffman, Robin McFee, J. Patrick Moulds, Alex Nettles, Elpidoforos Soteriades, Peter Thornquist, Edward Van Oeveren, Stephanie Weller, and Amanda Williams.

The development of the Leading Health Indicators was guided by an interagency work group and the Healthy People Steering Committee, which included Lois Albarelli, David R. Arday, David Atkins, Delton Atkinson, Linda A. Bailey, Olivia Carter-Pokras, Lynn Cates, Melissa H. Clarke, Marsha G. Davenport, Tuei Doong, Margaret Gilliam, Chuck Gollmar, William R. Harlan, James Harrell, Suzanne G. Haynes, Wanda K. Jones, Diane Justice, Nicole Lurie, Evelyn Kappeler, Richard J. Klein, Mary Ann MacKenzie, John Monahon, J. Henry Montes, Paul W. Nannis, Eileen Parish, Kate Rickard, Carol Roddy, Theresa Rogers, Dorita Sewell, Mary Beth Skupien, Philip B. Smith, Mark S. Smolinski, Christine G. Spain, Matthew Stagner, Irma Tetzloff, Betsy L. Thompson, Martina Vogel-Taylor, and Diane K. Wagener. Important contributions were provided by the Institute of Medicine, National Academy of Sciences Committee on Leading Health Indicators for Healthy People 2010, which included Susan Allan, Roger Bulger, Carole A. Chrvala, Donna D. Duncan, Neal Halfon, Barbara S. Hulka, Thomas J. Kean, Kelly Norsingle, Scott C. Ratzan, Stephen C. Schoenbaum, Mark Smith, Shoshanna Sofaer, Kathleen R. Stratton, and Robert B. Wallace.

Production for the Conference Edition was handled by staff of IQ Solutions, Inc., which included Denise Avery, Ted Buxton, Eleanor Hall, Michael Huddleston, E.J. King-Carter, James R. Libbey, Josue Martinez, Craig Packer, Meredith Pond, Lisa Smith, and Karen Stroud. Production for the second edition was carried out by staff at Social \& Health Services, Ltd., which included Nancy Klein, Mary Moien, Eric Moore, and Arlene Weitzman.

Finally, a sincere debt of gratitude to all contributors to Healthy People 2010, whose efforts greatly enhanced the development of this document. 



\section{Contents}

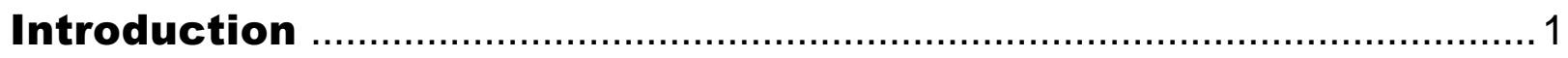

A Systematic Approach to Health Improvement ..............................

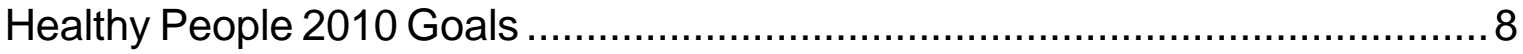

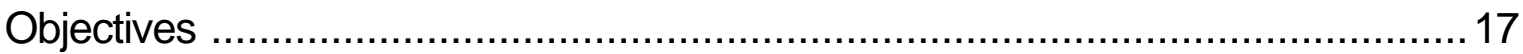

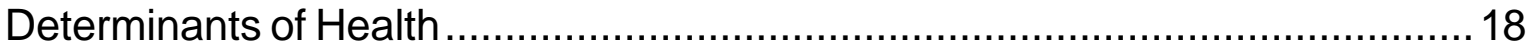

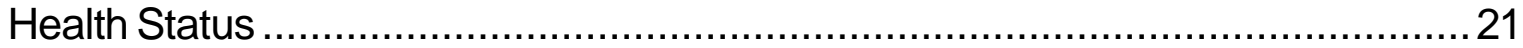

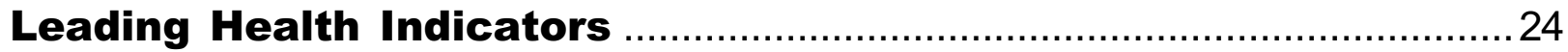

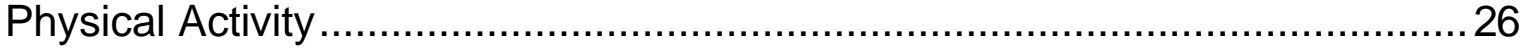

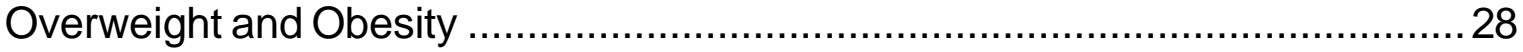

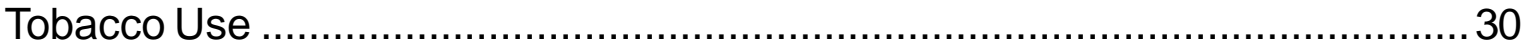

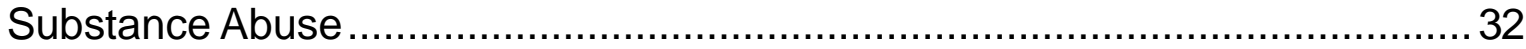

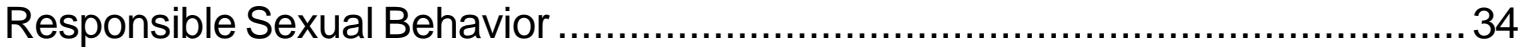

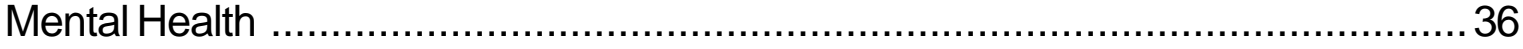

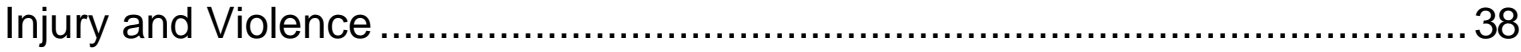

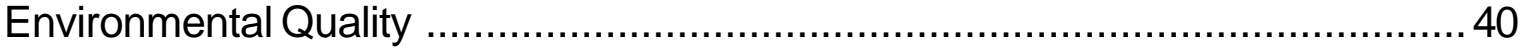

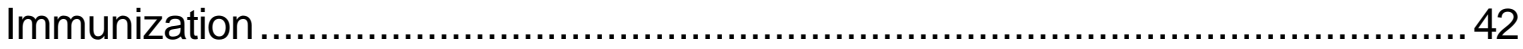

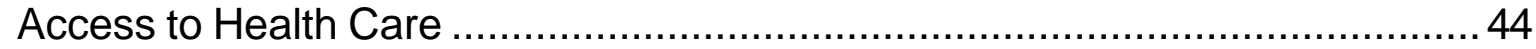

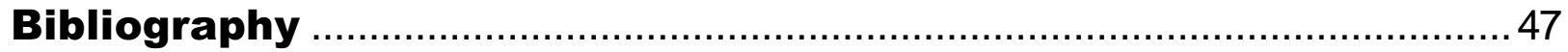

\section{Appendix:}

Short Titles for Healthy People 2010 Objectives ............................................53 



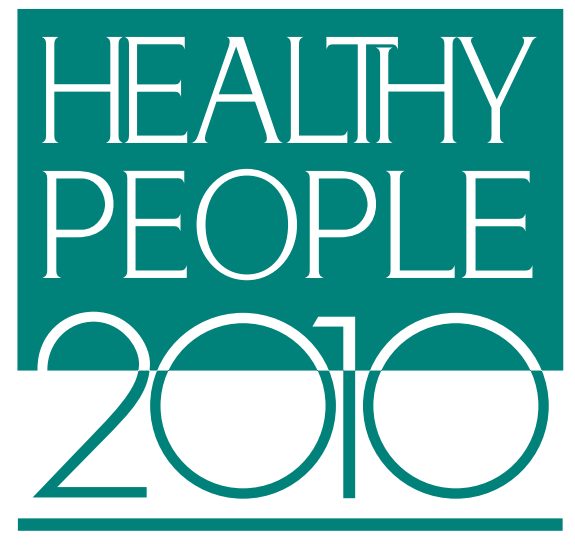

\section{Introduction}

Healthy People 2010 presents a comprehensive, nationwide health promotion and disease prevention agenda. It is designed to serve as a roadmap for improving the health of all people in the United States during the first decade of the 21 st century.

Like the preceding Healthy People 2000 initiative-which was driven by an ambitious, yet achievable, 10-year strategy for improving the Nation's health by the end of the 20th century-Healthy People 2010 is committed to a single, overarching purpose: promoting health and preventing illness, disability, and premature death.

\section{The History Behind the Healthy People 2010 Initiative}

Healthy People 2010 builds on initiatives pursued over the past two decades. In 1979, Healthy People: The Surgeon General's Report on Health Promotion and Disease Prevention provided national goals for reducing premature deaths and preserving independence for older adults. In 1980, another report, Promoting Health/Preventing Disease: Objectives for the Nation, set forth 226 targeted health objectives for the Nation to achieve over the next 10 years.

Healthy People 2000: National Health Promotion and Disease Prevention Objectives, released in 1990, identified health improvement goals and objectives to be reached by the year 2000. The Healthy People 2010 initiative continues in this tradition as an instrument to improve health for the

Healthy People 2010 is grounded in science, built through public consensus, and designed to measure progress. first decade of the 21 st century. 


\section{The Development of Healthy People 2010 Goals and Objectives}

Healthy People 2010 represents the ideas and expertise of a diverse range of individuals and organizations concerned about the Nation's health. The Healthy People Consortium-an alliance of more than 350 national organizations and 250 State public health, mental health, substance abuse, and environmental agencies—conducted three national meetings on the development of Healthy People 2010. In addition, many individuals and organizations gave testimony about health priorities at five Healthy People 2010 regional meetings held in late 1998.

On two occasions - in 1997 and in 1998 - the American public was given the opportunity to share its thoughts and ideas. More than 11,000 comments on draft materials were received by mail or via the Internet from individuals in every State, the District of Columbia, and Puerto Rico. All the comments received during the development of Healthy People 2010 can be viewed on the Healthy People Web site: http://www.health.gov/healthypeople/.

The final Healthy People 2010 objectives were developed by teams of experts from a variety of Federal agencies under the direction of Health and Human Services Secretary Donna Shalala, Assistant Secretary for Health and Surgeon General David Satcher, and former Assistant Secretaries for Health. The process was coordinated by the Office of Disease Prevention and Health Promotion, U.S. Department of Health and Human Services.

\section{The Goals of Healthy People 2010}

Healthy People 2010 is designed to achieve two overarching goals:

Increase quality and years of healthy life.

Eliminate health disparities.

These two goals are supported by specific objectives in 28 focus areas (see page 17). Each objective was developed with a target to be achieved by the year 2010. A full explanation of the two goals can be found in the next section of this document: "A Systematic Approach to Health Improvement." 


\section{The Relationship Between Individual and Community Health}

Over the years, it has become clear that individual health is closely linked to community health - the health of the community and environment in which individuals live, work, and play. Likewise, community health is profoundly affected by the collective beliefs, attitudes, and behaviors of everyone who lives in the community.

Indeed, the underlying premise of Healthy People 2010 is that the health of the individual is almost inseparable from the health of the larger community and that the health of every community in every State and territory determines the overall health status of the Nation. That is why the vision for Healthy People 2010 is "Healthy People in Healthy Communities."

\begin{tabular}{l} 
Community health is \\
profoundly affected \\
by the collective \\
beliefs, attitudes, \\
and behaviors of \\
everyone who lives in \\
the community. \\
\hline
\end{tabular}

\section{How Healthy People 2010 Will Improve the Nation's Health}

One of the most compelling and encouraging lessons learned from the Healthy People 2000 initiative is that we, as a Nation, can make dramatic progress in improving the Nation's health in a relatively short period of time. For example, during the past decade, we achieved significant reductions in infant mortality. Childhood vaccinations are at the highest levels ever recorded in the United States. Fewer teenagers are becoming parents. Overall, alcohol, tobacco, and illicit drug use is leveling off. Death rates for coronary heart disease and stroke have declined. Significant advances have been made in the diagnosis and treatment of cancer and in reducing unintentional injuries.

But we still have a long way to go. Diabetes and other chronic conditions continue to present a serious obstacle to public health. Violence and abusive behavior continue to ravage homes and communities across the country. Mental disorders continue to go undiagnosed and untreated. Obesity in adults has increased 50 percent over the past two decades. Nearly 40 percent of adults engage in no leisure time physical activity. Smoking among adolescents has increased in the past decade. And HIV/AIDS remains a serious health problem, now disproportionately affecting women and communities of color.

Healthy People 2010 will be the guiding instrument for addressing these and emerging health issues, reversing unfavorable trends, and expanding past achievements in health. 


\section{The Key Role of Community Partnerships}

Community partnerships, particularly when they reach out to nontraditional partners, can be among the most effective tools for improving health in communities.

For the past two decades, Healthy People has been used as a strategic management tool for the Federal Government, States, communities, and many other public- and private-sector partners. Virtually all States, the District of Columbia, and Guam have developed their

Partnerships are effective tools for improving health in communities. own Healthy People plans modeled after the national plan. Most States have tailored the national objectives to their specific needs.

Businesses; local governments; and civic, professional, and religious organizations also have been inspired by Healthy People to print immunization reminders, set up hotlines, change cafeteria menus, begin community recycling, establish worksite fitness programs, assess school health education curriculums, sponsor health fairs, and engage in myriad other activities.

\section{Everyone Can Help Achieve the Healthy People 2010 Objectives}

Addressing the challenge of health improvement is a shared responsibility that requires the active participation and leadership of the Federal Government, States, local governments, policymakers, health care providers, professionals, business executives, educators, community leaders, and the American public itself. Although administrative responsibility for the Healthy People 2010 initiative rests in the U.S. Department of Health and Human Services, representatives of all these diverse groups shared their experience, expertise, and ideas in developing the Healthy People 2010 goals and objectives.

Healthy People 2010, however, is just the beginning. The biggest challenges still stand before us, and we all have a role in building a healthier Nation.

Regardless of your age, gender, education level, income, race, ethnicity, cultural customs, language, religious beliefs, disability, sexual orientation, geographic location, or occupation, Healthy People 2010 is designed to be a valuable resource in determining how you can participate most effectively in improving the Nation's health. Perhaps you will recognize the need to be a more active participant in decisions affecting your own health or the health of your children or loved ones. Perhaps you will assume a leadership role in promoting healthier behaviors in your neighborhood or community. Or perhaps you will use your influence and social stature to advocate for and implement policies and programs that can improve dramatically the health of dozens, hundreds, thousands, or even millions of people.

Whatever your role, this document is designed to help you determine what you can do-in your home, community, business, or State - to help improve the Nation's health. 


\section{Other Information Is Available About Healthy People 2010}

Healthy People 2010: Understanding and Improving Health is the first of three parts in the Healthy People 2010 series. The second part, Healthy People 2010, contains detailed descriptions of 467 objectives to improve health. These objectives are organized into 28 specific focus areas. The third part, Tracking Healthy People 2010, provides a comprehensive review of the statistical measures that will be used to evaluate progress.

To receive more information about the Healthy People 2010 initiative, visit the Web site at http://www.health.gov/

Healthy People 2010 contains 467 objectives to improve health, organized into 28 focus areas. healthypeople/ or call 1-800-367-4725. To obtain copies of Healthy People 2010 documents in print or on a CD-ROM, see the order form at the end of this document. 


\section{Healthy People in Healthy Communities}

\section{A Systematic Approach to Health Improvement}

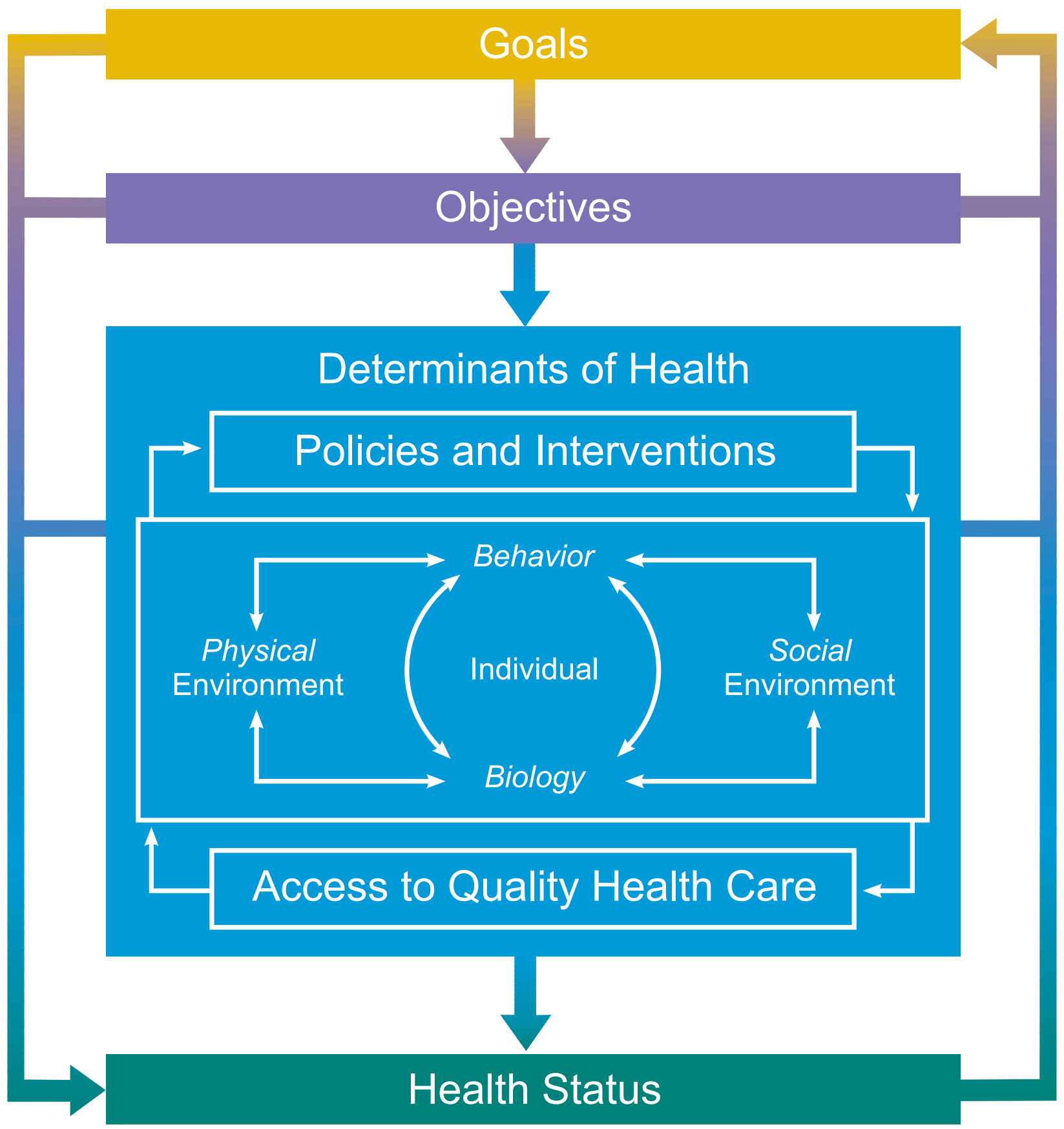




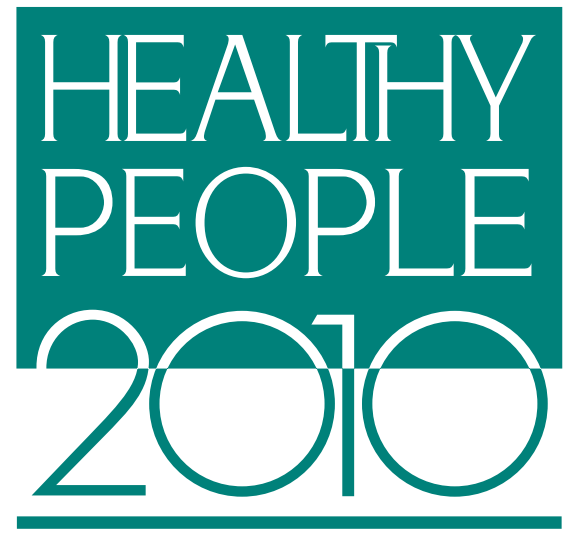

\section{A Systematic Approach to Health Improvement}

Healthy People 2010 is about improving health — the health of each individual, the health of communities, and the health of the Nation. However, the Healthy People 2010 goals and objectives cannot by themselves improve the health status of the Nation. Instead, they need to be recognized as part of a larger, systematic approach to health improvement.

This systematic approach to health improvement is composed of four key elements:

Goals

- Objectives

Determinants of health

- Health status

Whether this systematic approach is used to improve health on a national level, as in Healthy People 2010 , or to organize community action on a particular health issue, such as promoting smoking cessation, the components remain the same. The goals provide a general focus and direction. The goals, in turn, serve as a guide for developing a set of objectives that will measure actual progress within a specified amount of time. The objectives focus on the determinants of health, which encompass the combined effects of individual and community physical and social environments and the policies and interventions used to promote health, prevent disease, and ensure access to quality health care. The ultimate measure of success in any health improvement effort is the health status of the target

Successful community partnerships use a systematic approach to health improvement. population.

Healthy People 2010 is built on this systematic approach to health improvement. 


\section{Goal 1: Increase Quality and Years of Healthy Life}

The first goal of Healthy People 2010 is to help individuals of all ages increase life expectancy and improve their quality of life.

\section{Life Expectancy}

Life expectancy is the average number of years people born in a given year are expected to live based on a set of age-specific death rates. At the beginning of the 20th century, life expectancy at birth was 47.3 years. Fortunately, life expectancy has increased dramatically over the past 100 years (see figure 1). Today, the average life expectancy at birth is nearly 77 years.

Life expectancy for persons at every age group also has increased during the past century. Based on today's age-specific death rates, individuals aged 65 years can be expected to live an average of 18 more years, for a total of 83 years. Those aged 75 years can be expected to live an average of 11 more years, for a total of 86 years.

Differences in life expectancy between populations, however, suggest a substantial need and opportunity for improvement. At least 18 countries with populations of 1 million or more have life expectancies greater than the United States for both men and women (see figure 2).

Figure 1. Past and projected female and male life expectancy at birth, United States, 1900-2050.

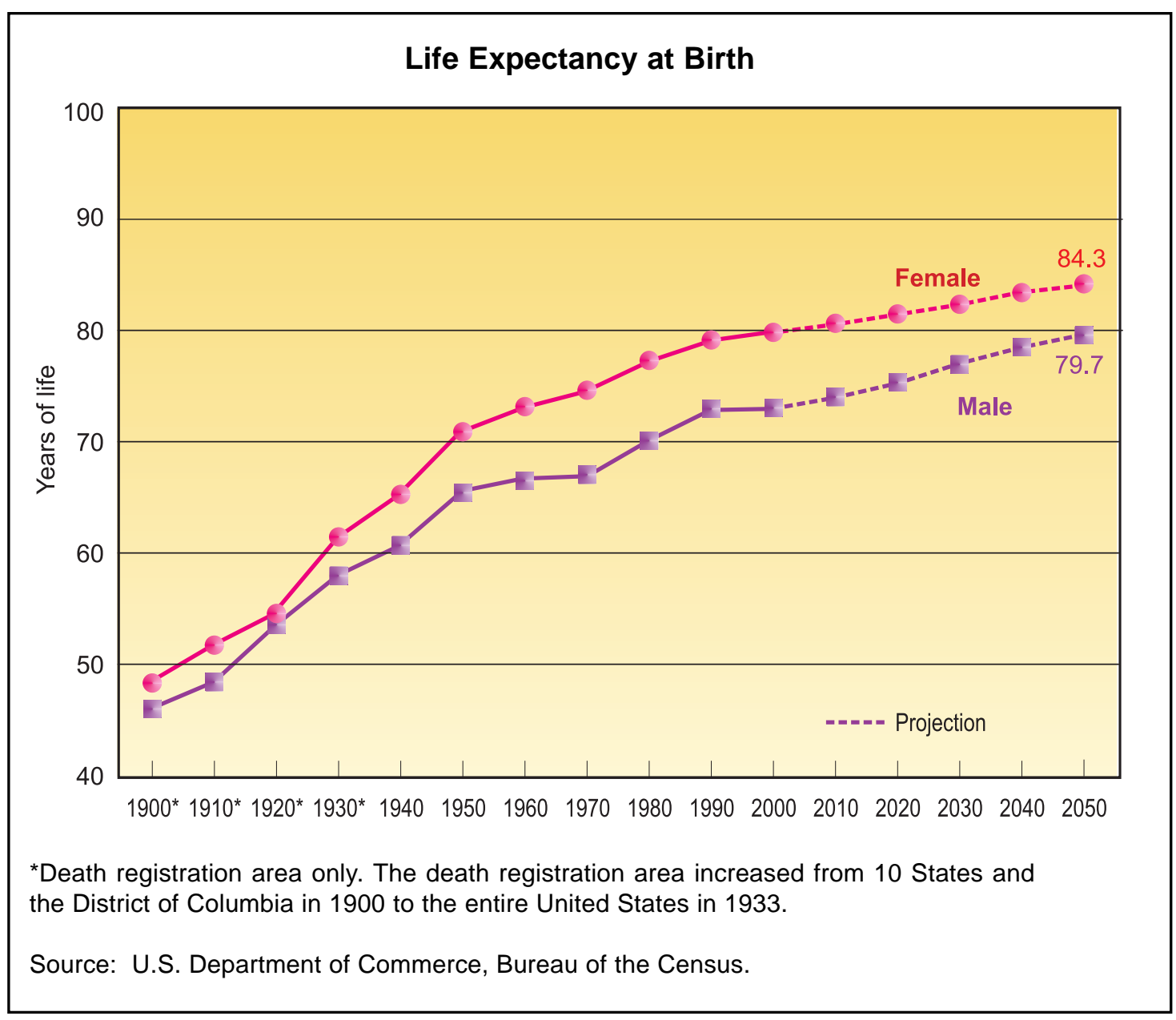


Figure 2. Life expectancy at birth by gender and ranked by selected countries, 1995.

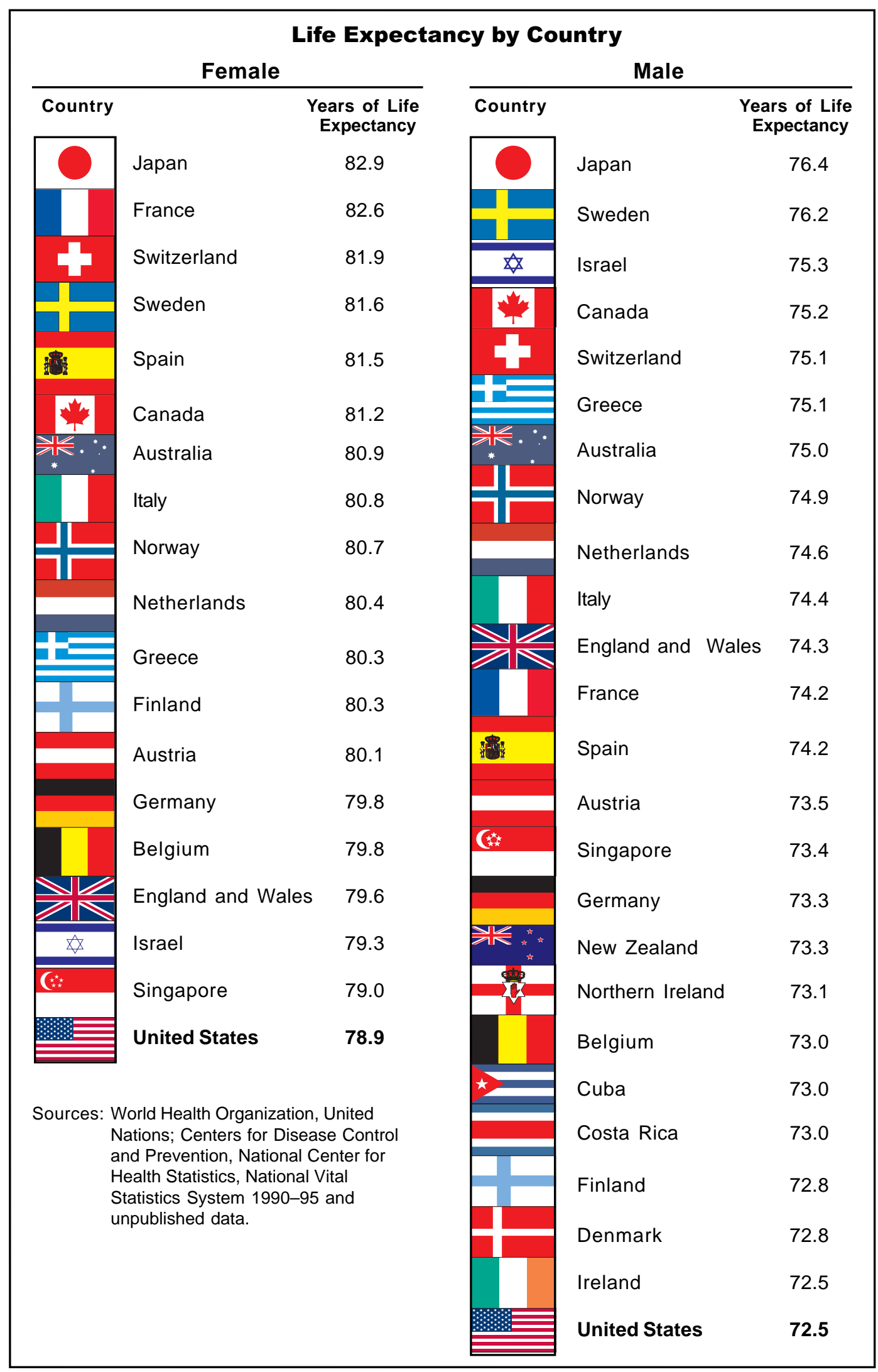


There are substantial differences in life expectancy among different population groups within the United States. For example, women outlive men by an average of 6 years. White women currently have the greatest life expectancy in the United States. The life expectancy for African American women has risen to be higher today than that for white men. People from households with an annual income of at least $\$ 25,000$ live an average of 3 to 7 years longer, depending on gender and race, than do people from households with annual incomes of less than $\$ 10,000$.

\section{Quality of Life}

Quality of life reflects a general sense of happiness and satisfaction with our lives and environment. General quality of life encompasses all aspects of life, including health, recreation, culture, rights, values, beliefs, aspirations, and the conditions that support a life containing these elements. Healthrelated quality of life reflects a personal sense of physical and mental health and the ability to react to factors in the physical and social environments. Health-related quality of life is more subjective than life expectancy and therefore can be more difficult to measure. Some tools have been developed to measure health-related quality of life.

Global assessments, in which a person rates his or her health as "poor," "fair," "good," "very good," or "excellent," can be reliable indicators of one's perceived health. In 1996, 90 percent of people in the United States reported their health as good, very good, or excellent.

Healthy days is another measure of health-related quality of life that estimates the number of days of poor or impaired physical and mental health in the past 30 days. In 1998, adults averaged 5.5 days during the past month when their physical or mental health was not good-including 1.8 days when they were not able to do their usual activities. However, 52 percent of adults reported having good physical and mental health for the entire month in contrast with 10 percent of adults who were unhealthy for all 30 days. Typically, younger adults report more mentally unhealthy days while older adults report more physically unhealthy days.

Years of healthy life is a combined measure developed for the Healthy People initiative. The difference between life expectancy and years of healthy life reflects the average amount of time spent in less than optimal health because of chronic or acute limitations. Years of healthy life increased in 1996 to 64.2 years, a level that was only slightly above the 64.0 years at the beginning of the decade. During the same period, life expectancy increased a full year.

As with life expectancy, various population groups can show dramatic differences in quality of life. For example, people in the lowest income households are five times more likely to report their health as fair or poor than people in the highest income households (see figure 3). A higher percentage of women report their health as fair or poor compared to men. Adults in rural areas are 36 percent more likely to report their health status as fair or poor than are adults in urban areas.

\section{Achieving a Longer and Healthier Life—the Healthy People Perspective}

Healthy People 2010 seeks to increase life expectancy and quality of life over the next 10 years by helping individuals gain the knowledge, motivation, and opportunities they need to make informed decisions about their health. At the same time, Healthy People 2010 encourages local and State leaders to develop communitywide and statewide efforts that promote healthy behaviors, create healthy environments, and increase access to high-quality health care. Because individual and community health are virtually inseparable, both the individual and the community need to do their parts to increase life expectancy and improve quality of life. 
Figure 3. Percentage of persons with perceived fair or poor health status by household income, United States, 1995.

\section{Relationship Between Household Income and Fair or Poor Health Status}

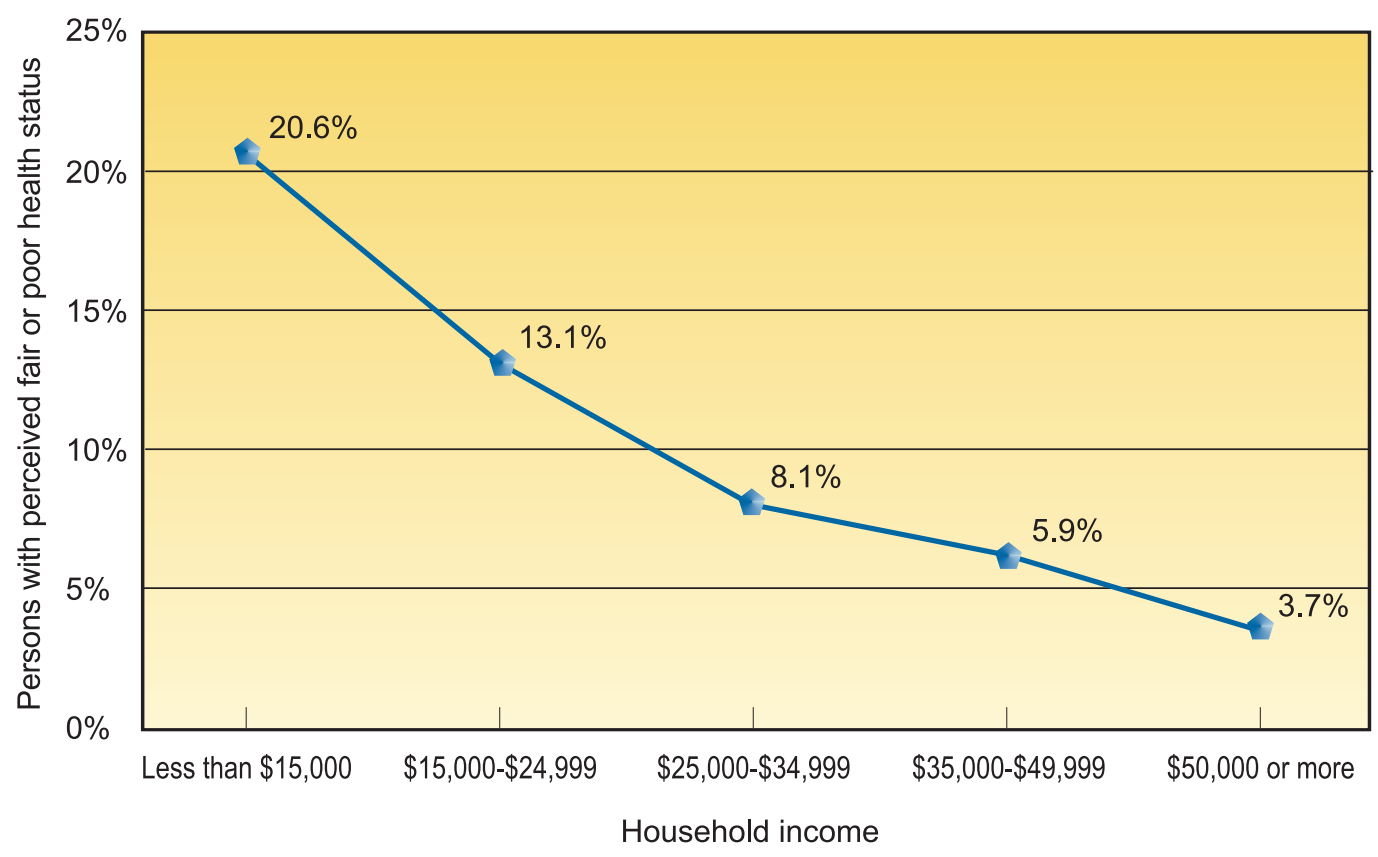

Source: Centers for Disease Control and Prevention, National Center for Health Statistics. National Health Interview Survey. 1995.

\section{Goal 2: Eliminate Health Disparities}

The second goal of Healthy People 2010 is to eliminate health disparities among segments of the population, including differences that occur by gender, race or ethnicity, education or income, disability, geographic location, or sexual orientation. This section highlights ways in which health disparities can occur among various demographic groups in the United States.

\section{Gender}

Whereas some differences in health between men and women are the result of biological differences, others are more complicated and require greater attention and scientific exploration. Some health differences are obviously gender specific, such as cervical and prostate cancers.

Overall, men have a life expectancy that is 6 years less than that of women and have higher death rates for each of the 10 leading causes of death. For example, men are two times more likely than women to die from unintentional injuries and four times more likely than women to die from firearmrelated injuries. Although overall death rates for women may currently be lower than for men, women have shown increased death rates over the past decade in areas where men have experienced improvements, such as lung cancer. Women are also at greater risk for Alzheimer's disease than men are and twice as likely as men to be affected by major depression. 


\section{Race and Ethnicity}

Current information about the biologic and genetic characteristics of African Americans, Hispanics, American Indians, Alaska Natives, Asians, Native Hawaiians, and Pacific Islanders does not explain the health disparities experienced by these groups compared with the white, non-Hispanic population in the United States. These disparities are believed to be the result of the complex interaction among genetic variations, environmental factors, and specific health behaviors.

Even though the Nation's infant mortality rate is down, the infant death rate among African Americans is still more than double that of whites. Heart disease death rates are more than 40 percent higher for African Americans than for whites. The death rate for all cancers is 30 percent higher for African Americans than for whites; for prostate cancer, it is more than double that for whites. African American women have a higher death rate from breast cancer despite having a mammography screening rate that is nearly the same as the rate for white women. The death rate from HIV/AIDS for African Americans is more than seven times that for whites; the rate of homicide is six times that for whites.

Hispanics living in the United States are almost twice as likely to die from diabetes as are nonHispanic whites. Although constituting only 11 percent of the total population in 1996, Hispanics accounted for 20 percent of the new cases of tuberculosis. Hispanics also have higher rates of high blood pressure and obesity than non-Hispanic whites. There are differences among Hispanic populations as well. For example, whereas the rate of low birth weight infants is lower for the total Hispanic population compared with that of whites, Puerto Ricans have a low birth weight rate that is 50 percent higher than the rate for whites.

American Indians and Alaska Natives have an infant death rate almost double that for whites. The rate of diabetes for this population group is more than twice that for whites. The Pima of Arizona have one of the highest rates of diabetes in the world. American Indians and Alaska Natives also have disproportionately high death rates from unintentional injuries and suicide.

Asians and Pacific Islanders, on average, have indicators of being one of the healthiest population groups in the United States. However, there is great diversity within this population group, and health disparities for some specific segments are quite marked. Women of Vietnamese origin, for example, suffer from cervical cancer at nearly five times the rate for white women. New cases of hepatitis and tuberculosis are also higher in Asians and Pacific Islanders living in the United States than in whites.

\section{Income and Education}

Inequalities in income and education underlie many health disparities in the United States. Income and education are intrinsically related and often serve as proxy measures for each other (see figure 4). In general, population groups that suffer the worst health status are also those that have the highest poverty rates and the least education. Disparities in income and education levels are associated with differences in the occurrence of illness and death, including heart disease, diabetes, obesity, elevated blood lead level, and low birth weight. Higher incomes permit increased access to medical care, enable people to afford better housing and live in safer neighborhoods, and increase the opportunity to engage in health-promoting behaviors. 
Figure 4. Relationship between education and median household income among adults aged 25 years and older, by gender, United States, 1996.

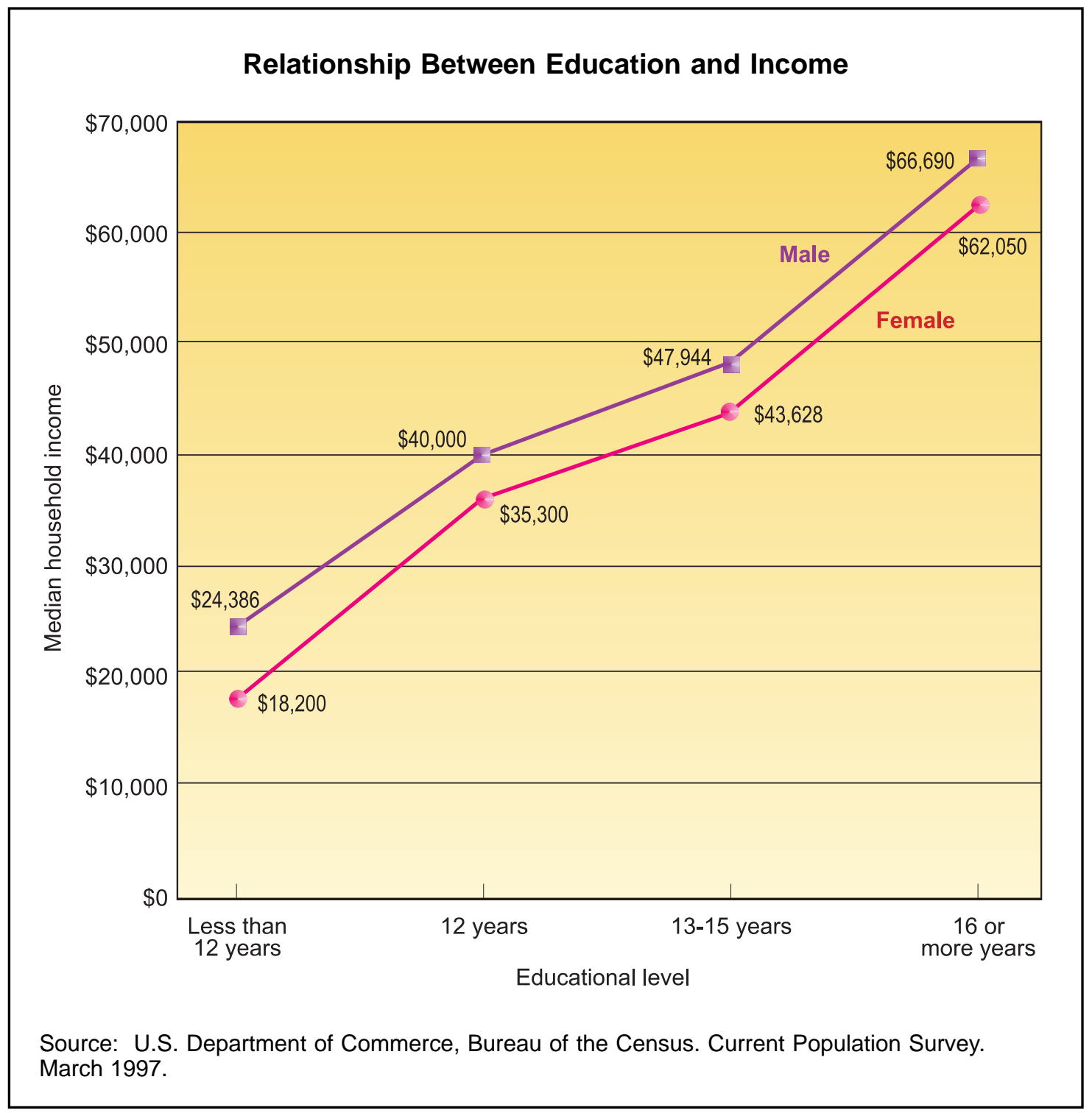

Income inequality in the United States has increased over the past three decades. There are distinct demographic differences in poverty by race, ethnicity, and household composition (see figure 5) as well as geographical variations in poverty across the United States. Recent health gains for the U.S. population as a whole appear to reflect achievements among the higher socioeconomic groups; lower socioeconomic groups continue to lag behind. 


\section{Healthy People 2010 Goals}

Figure 5. Percentage of persons below the poverty level by race and ethnicity and type of household, United States, 1996.

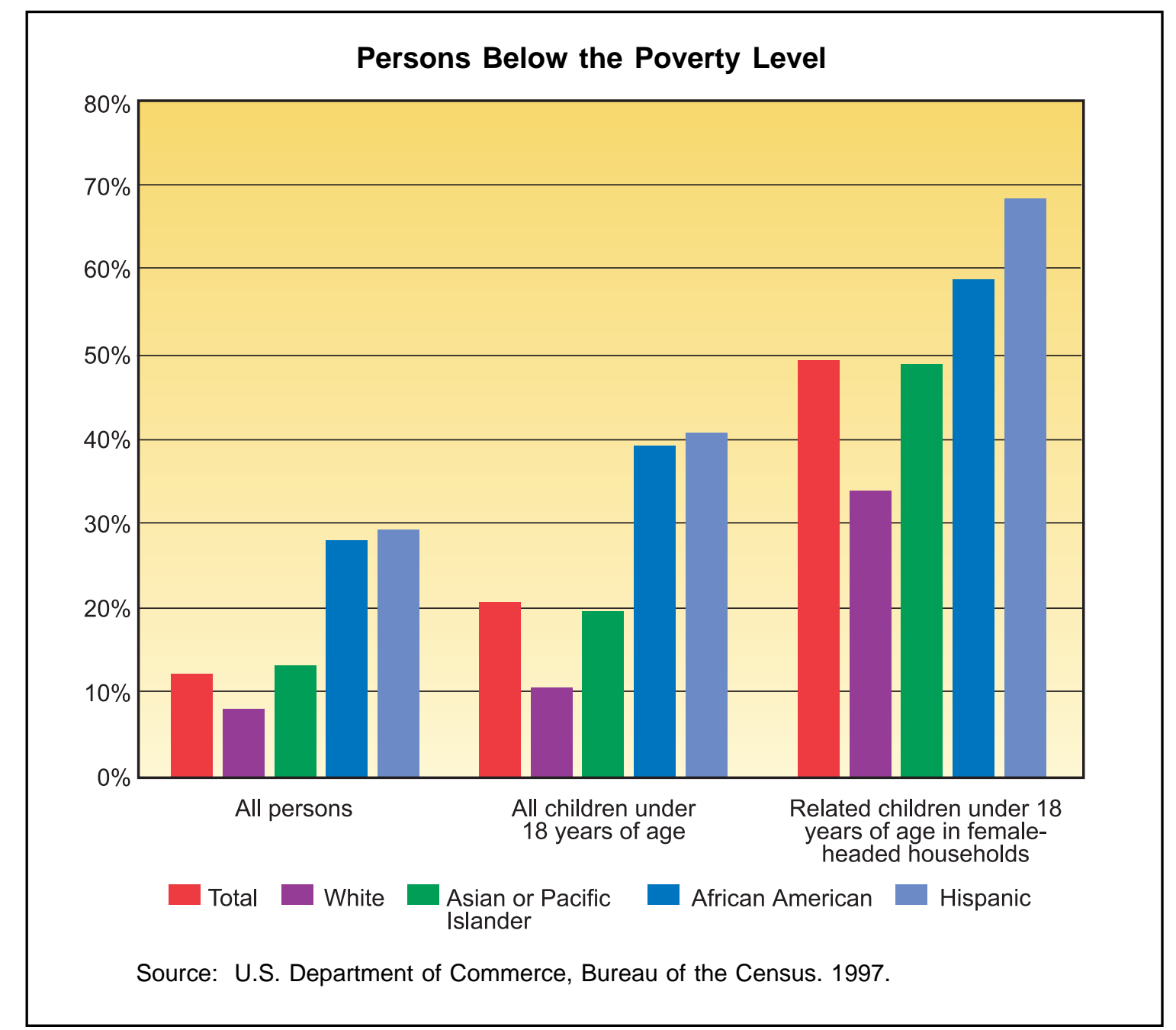

Overall, those with higher incomes tend to fare better than those with lower incomes. For example, among white men aged 65 years, those in the highest income families could expect to live more than 3 years longer than those in the lowest income families. The percentage of people in the lowest income families reporting limitation in activity caused by chronic disease is three times that of people in the highest income families.

The average level of education in the U.S. population has increased steadily over the past several decades - an important achievement given that more years of education usually translate into more years of life. For women, the amount of education achieved is a key determinant of the welfare and survival of their children. Higher levels of education also may increase the likelihood of obtaining or understanding health-related information needed to develop health-promoting behaviors and beliefs in prevention. But again, educational attainment differs by race and ethnicity (see figure 6). Among people aged 25 to 64 years in the United States, the overall death rate for those with less than 12 years of education is more than twice that for people with 13 or more years of education. The infant mortality rate is almost double for infants of mothers with less than 12 years of education compared with those with an educational level of 13 or more years. 
Figure 6. Percentage of adults aged 25 to 64 years by educational level and race, and ethnicity, United States, 1996.

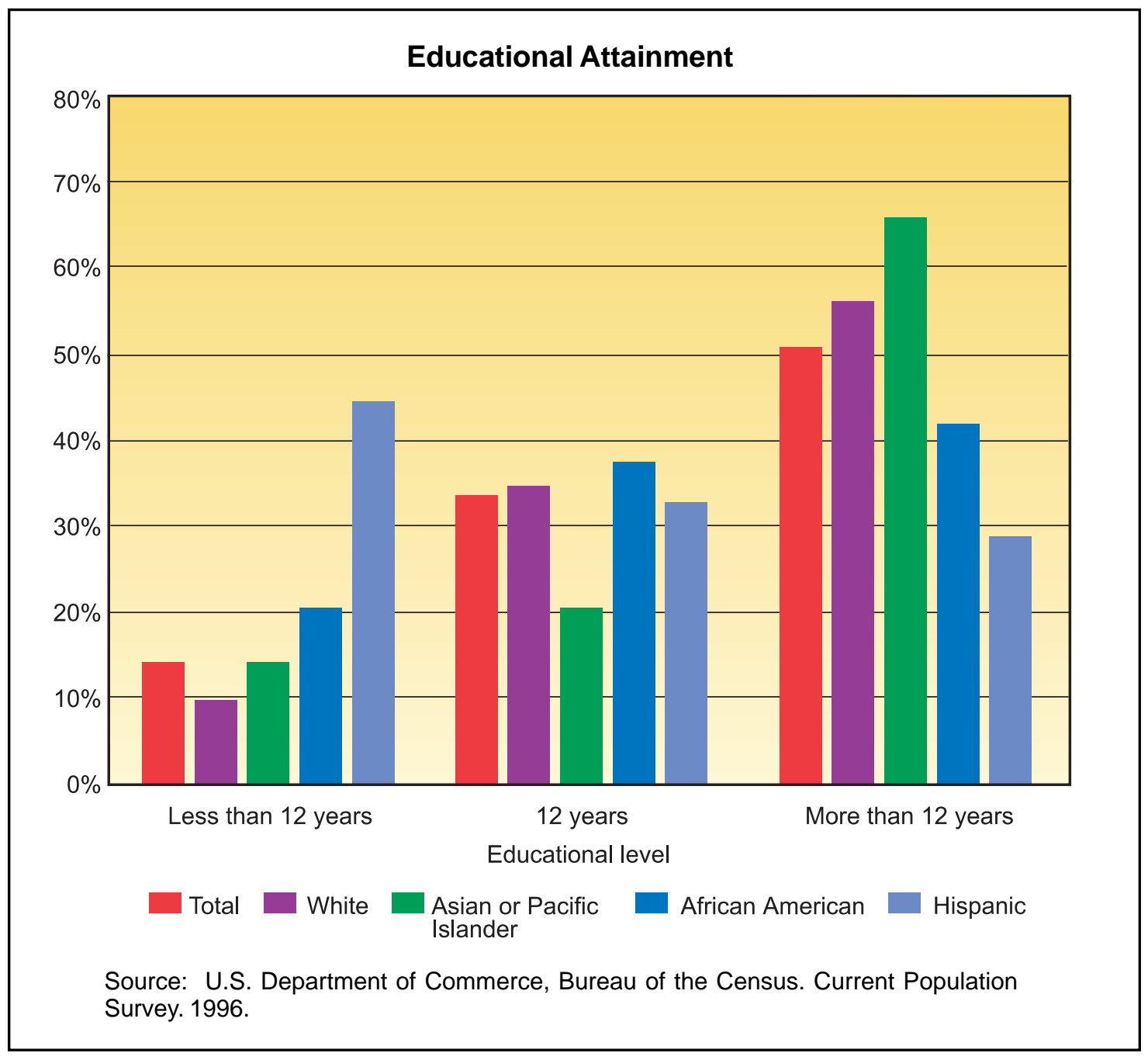

\section{Disability}

People with disabilities are identified as persons having an activity limitation, who use assistance, or who perceive themselves as having a disability. In 1994, 54 million people in the United States, or roughly 21 percent of the population, had some level of disability. Although rates of disability are relatively stable or falling slightly for people aged 45 years and older, rates are on the rise among the younger population. People with disabilities tend to report more anxiety, pain, sleeplessness, and days of depression and fewer days of vitality than do people without activity limitations. People with disabilities also have other disparities, including lower rates of physical activity and higher rates of obesity. Many people with disabilities lack access to health services and medical care. 


\section{Geographic Location}

Twenty-five percent of Americans live in rural areas, that is, places with fewer than 2,500 residents. Injury-related death rates are 40 percent higher in rural populations than in urban populations. Heart disease, cancer, and diabetes rates exceed those for urban areas. People living in rural areas are less likely to use preventive screening services, exercise regularly, or wear safety belts. In 1996, 20 percent of the rural population was uninsured compared with 16 percent of the urban population. Timely access to emergency services and the availability of specialty care are other issues for this population group.

\section{Sexual Orientation}

America's gay and lesbian population comprises a diverse community with disparate health concerns. Major health issues for gay men are HIV/AIDS and other sexually transmitted diseases, substance abuse, depression, and suicide. Gay male adolescents are two to three times more likely than their peers to attempt suicide. Some evidence suggests lesbians have higher rates of smoking, overweight, alcohol abuse, and stress than heterosexual women. The issues surrounding personal, family, and social acceptance of sexual orientation can place a significant burden on mental health and personal safety.

\section{Achieving Equity-The Healthy People Perspective}

Although the diversity of the American population may be one of the Nation's greatest assets, it also represents a range of health improvement challenges - challenges that must be addressed by individuals, the community and State in which they live, and the Nation as a whole.

Healthy People 2010 recognizes that communities, States, and national organizations will need to take a multidisciplinary approach to achieving health equity — an approach that involves improving health, education, housing, labor, justice, transportation, agriculture, and the environment, as well as data collection itself. In fact, current data collection methods make it impossible to assess accurately the health status for some populations, particularly relatively small ones. However, the greatest opportunities for reducing health disparities are in empowering individuals to make informed health care decisions and in promoting communitywide safety, education, and access to health care.

Healthy People 2010 is firmly dedicated to the principle that—regardless of age, gender, race or ethnicity, income, education, geographic location, disability, and sexual orientation-every person in every community across the Nation deserves equal access to comprehensive, culturally competent, community-based health care systems that are committed to serving the needs of the individual and promoting community health. 
The Nation's progress in achieving the two goals of Healthy People 2010 will be monitored through 467 objectives in 28 focus areas. Many objectives focus on interventions designed to reduce or eliminate illness, disability, and premature death among individuals and communities. Others focus on broader issues, such as improving access to quality health care, strengthening public health services, and improving the availability and dissemination of health-related information. Each objective has a target for specific improvements to be achieved by the year 2010.

Together, these objectives reflect the depth of scientific knowledge as well as the breadth of diversity in the Nation's communities. More importantly, they are designed to help the Nation achieve Healthy People 2010's two overarching goals and realize the vision of healthy people living in healthy communities.

A list of the short titles of all Healthy People 2010 objectives by focus area can be found in the Appendix. In addition, Healthy People 2010 provides an overview of the issues, trends, and opportunities for action in each of the 28 focus areas. It also contains detailed language of each objective, underlying rationale, target for the year 2010, and national data tables of its measures.

\section{Healthy People 2010 Focus Areas}

1. Access to Quality Health Services

2. Arthritis, Osteoporosis, and Chronic Back Conditions

3. Cancer

4. Chronic Kidney Disease

5. Diabetes

6. Disability and Secondary Conditions

7. Educational and Community-Based Programs

8. Environmental Health

9. Family Planning

10. Food Safety

11. Health Communication

12. Heart Disease and Stroke

13. HIV

14. Immunization and Infectious Diseases

15. Injury and Violence Prevention

16. Maternal, Infant, and Child Health

17. Medical Product Safety

18. Mental Health and Mental Disorders

19. Nutrition and Overweight

20. Occupational Safety and Health

21. Oral Health

22. Physical Activity and Fitness

23. Public Health Infrastructure

24. Respiratory Diseases

25. Sexually Transmitted Diseases

26. Substance Abuse

27. Tobacco Use

28. Vision and Hearing 


\section{Determinants of Health}

Topics covered by the objectives in Healthy People 2010 reflect the array of critical influences that determine the health of individuals and communities.

For example, individual behaviors and environmental factors are responsible for about 70 percent of all premature deaths in the United States. Developing and implementing policies and preventive interventions that effectively address these determinants of health can reduce the burden of illness, enhance quality of life, and increase longevity.

Individual biology and behaviors influence health through their interaction with each other and with the individual's social and physical environments. In addition, policies and interventions can improve health by targeting factors related to individuals and their environments, including access to quality health care (see figure 7).

Figure 7. Determinants of health.

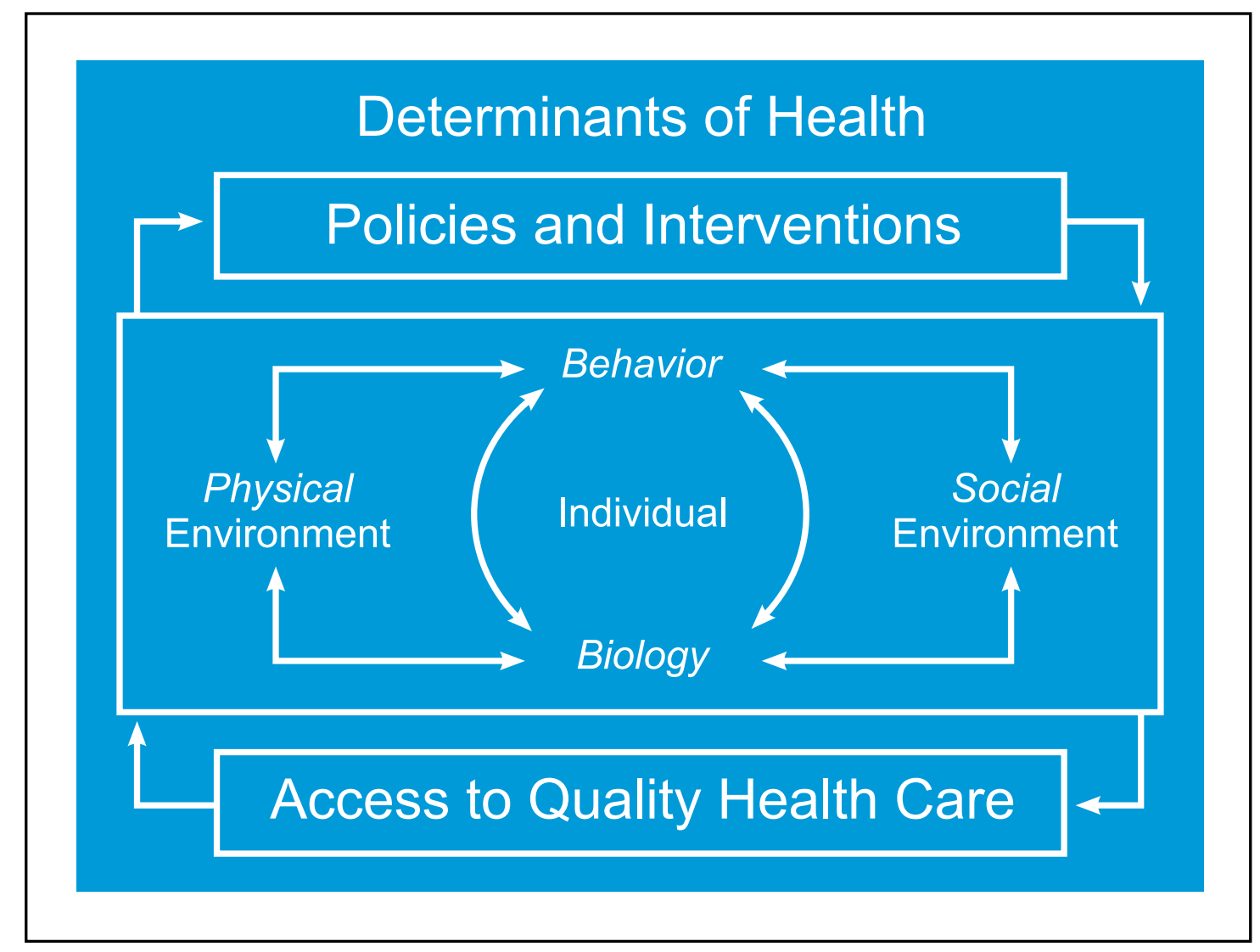


Biology refers to the individual's genetic makeup (those factors with which he or she is born), family history (which may suggest risk for disease), and the physical and mental health problems acquired during life. Aging, diet, physical activity, smoking, stress, alcohol or illicit drug abuse, injury or violence, or an infectious or toxic agent may result in illness or disability and can produce a "new" biology for the individual.

Behaviors are individual responses or reactions to internal stimuli and external conditions. Behaviors can have a reciprocal relationship to biology; in other words, each can react to the other. For example, smoking (behavior) can alter the cells in the lung and result in shortness of breath, emphysema, or cancer (biology) that then may lead an individual to stop smoking (behavior). Similarly, a family history that includes heart disease (biology) may motivate an individual to develop good eating habits, avoid tobacco, and maintain an active lifestyle (behaviors), which may prevent his or her own development of heart disease (biology).

Personal choices and the social and physical environments surrounding individuals can shape behaviors. The social and physical environments include all factors that affect the life of individuals, positively or negatively, many of which may not be under their immediate or direct control.

Social environment includes interactions with family, friends, coworkers, and others in the community. It also encompasses social institutions, such as law enforcement, the workplace, places of worship, and schools. Housing, public transportation, and the presence or absence of violence in the community are among other components of the social environment. The social environment has a profound effect on individual health, as well as on the health of the larger community, and is unique because of cultural customs; language; and personal, religious, or spiritual beliefs. At the same time, individuals and their behaviors contribute to the quality of the social environment.

Physical environment can be thought of as that which can be seen, touched, heard, smelled, and tasted. However, the physical environment also contains less tangible elements, such as radiation and ozone. The physical environment can harm individual and community health, especially when individuals and communities are exposed to toxic substances; irritants; infectious agents; and physical hazards in homes, schools, and worksites. The physical environment also can promote good health, for example, by providing clean and safe places for people to work, exercise, and play.

Policies and interventions can have a powerful and positive effect on the health of individuals and the community. Examples include health promotion campaigns to prevent smoking; policies mandating child restraints and safety belt use in automobiles; disease prevention services, such as immunization of children, adolescents, and adults; and clinical services, such as enhanced mental health care. Policies and interventions that promote individual and community health may be implemented by a variety of agencies, such as transportation, education, energy, housing, labor, justice, and other venues, or through places of worship, community-based organizations, civic groups, and businesses. 


\section{Determinants of Health}

The health of individuals and communities also depends greatly on access to quality health care. Expanding access to quality health care is important to eliminate health disparities and to increase the quality and years of healthy life for all people living in the United States. Health care in the broadest sense not only includes services received through health care providers but also health information and services received through other venues in the community.

The determinants of health—individual biology and behavior, physical and social environments, policies and interventions, and access to quality health care-have a profound effect on the health of individuals, communities, and the Nation. An evaluation of these determinants is an important part of developing any strategy to improve health.

Our understanding of these determinants and how they relate to one another, coupled with our understanding of how individual and community health affects the health of the Nation, is perhaps the most important key to achieving our Healthy People 2010 goals of increasing the quality and years of life and of eliminating the Nation's health disparities. 


\section{Health Status}

To understand the health status of a population, it is essential to monitor and evaluate the consequences of the determinants of health.

The health status of the United States is a description of the health of the total population, using information representative of most people living in this country. For relatively small population groups, however, it may not be possible to draw accurate conclusions about their health using current data collection methods. The goal of eliminating health disparities will necessitate improved collection and use of standardized data to identify correctly disparities among select population groups.

Health status can be measured by birth and death rates, life expectancy, quality of life, morbidity from specific diseases, risk factors, use of ambulatory care and inpatient care, accessibility of health personnel and facilities, financing of health care, health insurance coverage, and many other factors. The information used to report health status comes from a variety of sources, including birth and death records; hospital discharge data; and health information collected from health care records, personal interviews, physical examinations, and telephone surveys. These measures are monitored on an annual basis in the United States and are reported in a variety of publications, including Health, United States, and Healthy People Reviews.

The leading causes of death are used frequently to describe the health status of the Nation. Over the past 100 years, the Nation has seen a great deal of change in the leading causes of death (see figure 8). At the beginning of the 1900s, infectious diseases ran rampant in the United States and worldwide and topped the leading causes of death. A century later, with the control of many infectious agents and the increasing age of the population, chronic diseases top the list.

A very different picture emerges when the leading causes of death are viewed for various population groups. Unintentional injuries, mainly motor vehicle crashes, are the fifth leading cause of death for the total population, but they are the leading cause of death for people aged 1 to 44 years. Similarly, HIV/AIDS is the 14th leading cause of death for the total population but the leading cause of death for African American men aged 25 to 44 years (see figure 9).

The leading causes of death in the United States generally result from a mix of behaviors; injury, violence, and other factors in the environment; and the unavailability or inaccessibility of quality health services. Understanding and monitoring behaviors, environmental factors, and community health systems may prove more useful to monitoring the Nation's true health, and in driving health improvement activities, than the death rates that reflect the cumulative impact of these factors. This more complex approach has served as the basis for developing the Leading Health Indicators. 


\section{Health Status}

Figure 8. The leading causes of death as a percentage of all deaths in the United States, 1900 and 1997.

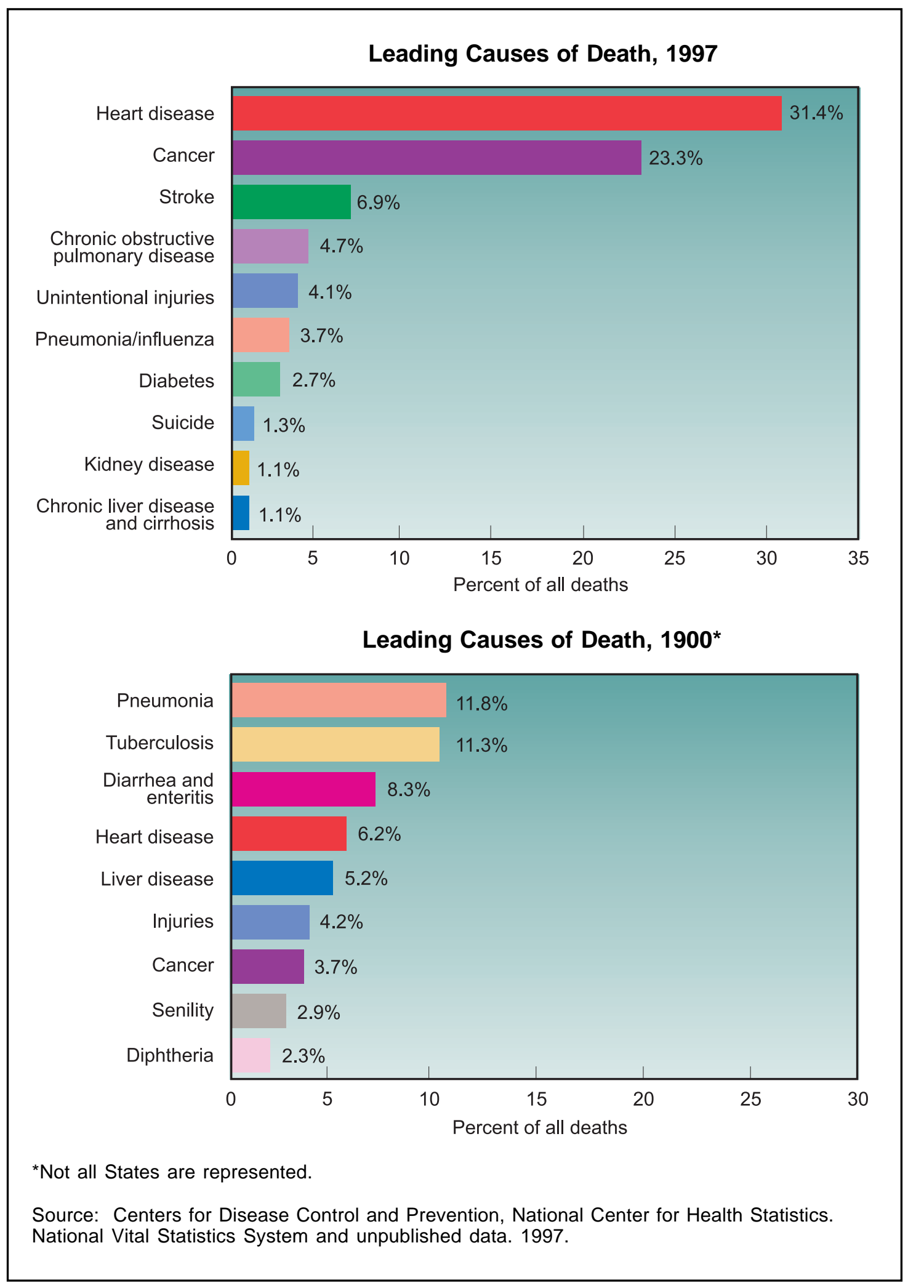


Figure 9. The three leading causes of death by age group, United States, 1997.

\section{Leading Causes of Death by Age Group}

\begin{tabular}{|c|c|}
\hline Under 1 Year & Number of Deaths \\
\hline Birth defects & 6,178 \\
\hline Disorders related to premature birth & 3,925 \\
\hline Sudden infant death syndrome & 2,991 \\
\hline \multicolumn{2}{|l|}{ 1-4 Years } \\
\hline Unintentional injuries & 2,005 \\
\hline Birth defects & 589 \\
\hline Cancer & 438 \\
\hline \multicolumn{2}{|l|}{ 5-14 Years } \\
\hline Unintentional injuries & 3,371 \\
\hline Cancer & 1,030 \\
\hline Homicide & 457 \\
\hline \multicolumn{2}{|l|}{ 15-24 Years } \\
\hline Unintentional injuries & 13,367 \\
\hline Homicide & 6,146 \\
\hline Suicide & 4,186 \\
\hline \multicolumn{2}{|l|}{ 25-44 Years } \\
\hline Unintentional injuries & 27,129 \\
\hline Cancer & 21,706 \\
\hline Heart disease & 16,513 \\
\hline \multicolumn{2}{|l|}{ 45-64 Years } \\
\hline Cancer & 131,743 \\
\hline Heart disease & 101,235 \\
\hline Unintentional injuries & 17,521 \\
\hline \multicolumn{2}{|l|}{65 Years and Older } \\
\hline Heart disease & 606,913 \\
\hline Cancer & 382,913 \\
\hline Stroke & 140,366 \\
\hline
\end{tabular}

Bullets above link to the conditions listed in the charts in figure 8.

Source: Centers for Disease Control and Prevention, National Center for Health Statistics. National Vital Statistics System. 1999. 


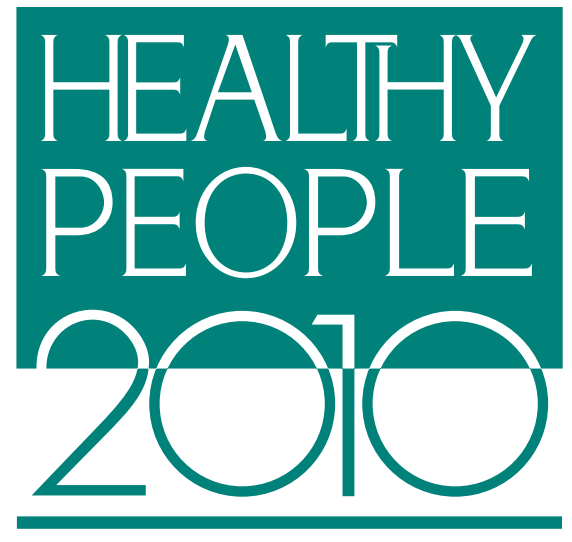

\section{Leading Health Indicators}

The Leading Health Indicators reflect the major public health concerns in the United States and were chosen based on their ability to motivate action, the availability of data to measure their progress, and their relevance as broad public health issues.

The Leading Health Indicators illuminate individual behaviors, physical and social environmental factors, and important health system issues that greatly affect the health of individuals and communities. Underlying each of these indicators is the significant influence of income and education (see Income and Education, page 12).

The process of selecting the Leading Health Indicators mirrored the collaborative and extensive efforts undertaken to develop Healthy People 2010. The process was led by an interagency work group within the U.S. Department of Health and Human Services. Individuals and organizations provided comments at national and regional meetings or via mail and the Internet. A report by the Institute of Medicine, National Academy of Sciences, provided several scientific models on

\section{Leading Health Indicators}

- Physical activity

- Overweight and obesity

- Tobacco use

- Substance abuse

- Responsible sexual

$$
\text { behavior }
$$

- Mental health

- Injury and violence

- Environmental quality

- Immunization

- Access to health care 
which to support a set of indicators. Focus groups were used to ensure that the indicators are meaningful and motivating to the public.

For each of the Leading Health Indicators, specific objectives derived from Healthy People 2010 will be used to track progress. This small set of measures will provide a snapshot of the health of the Nation. Tracking and communicating progress on the Leading Health Indicators through national- and Statelevel report cards will spotlight achievements and challenges in the next decade. The Leading Health Indicators serve as a link to the 467 objectives in Healthy People 2010 and can become the basic building blocks for community health initiatives.

\begin{tabular}{l}
\hline A major challenge \\
throughout the history \\
of Healthy People has \\
been to balance a \\
comprehensive set of \\
health objectives with \\
a smaller set of health \\
priorities.
\end{tabular}

The Leading Health Indicators are intended to help everyone more easily understand the importance of health promotion and disease prevention and to encourage wide participation in improving health in the next decade. Developing strategies and action plans to address one or more of these indicators can have a profound effect on increasing the quality of life and the years of healthy life and on eliminating health disparities_creating healthy people in healthy communities. 


\section{Leading Health Indicator}

Regular physical activity throughout life is important for maintaining a healthy body, enhancing psychological well-being, and preventing premature death.

In 1999, 65 percent of adolescents engaged in the recommended amount of physical activity. In 1997, only 15 percent of adults performed the recommended amount of physical activity, and 40 percent of adults engaged in no leisure-time physical activity.

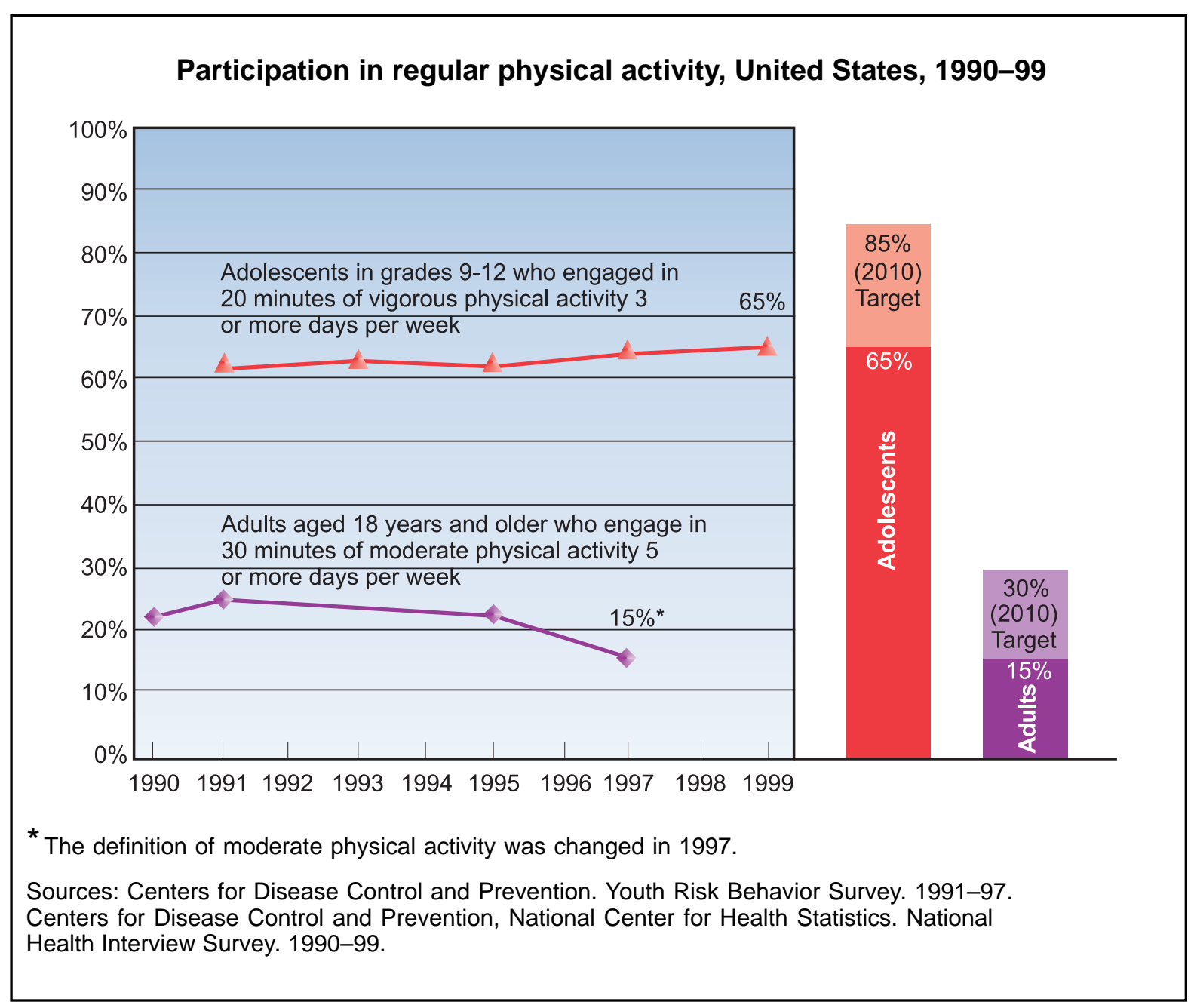

The objectives selected to measure progress among adolescents and adults for this Leading Health Indicator are presented below. These are only indicators and do not represent all the physical activity and fitness objectives included in Healthy People 2010.

\section{2-7. Increase the proportion of adolescents who engage in vigorous physical activity that promotes cardiorespiratory fitness 3 or more days per week for 20 or more minutes per occasion.}

22-2. Increase the proportion of adults who engage regularly, preferably daily, in moderate physical activity for at least $\mathbf{3 0}$ minutes per day. 


\section{Health Impact of Physical Activity}

Regular physical activity is associated with lower death rates for adults of any age, even when only moderate levels of physical activity are performed. Regular physical activity decreases the risk of death from heart disease, lowers the risk of developing diabetes, and is associated with a decreased risk of colon cancer. Regular physical activity helps prevent high blood pressure and helps reduce blood pressure in persons with elevated levels.

Regular physical activity also:

- Increases muscle and bone strength.

Increases lean muscle and helps decrease body fat.

- Aids in weight control and is a key part of any weight loss effort.

- Enhances psychological well-being and may even reduce the risk of developing depression.

Appears to reduce symptoms of depression and anxiety and to improve mood.

In addition, children and adolescents need weight-bearing exercise for normal skeletal development, and young adults need such exercise to achieve and maintain peak bone mass. Older adults can improve and maintain strength and agility with regular physical activity. This can reduce the risk of falling, helping older adults maintain an independent living status. Regular physical activity also increases the ability of people with certain chronic, disabling conditions to perform activities of daily living.

\section{Populations With Low Rates of Physical Activity}

- Women generally are less active than men at all ages.

- People with lower incomes and less education are typically not as physically active as those with higher incomes and education.

African Americans and Hispanics are generally less physically active than whites.

- Adults in northeastern and southern States tend to be less active than adults in North-Central and Western States.

- People with disabilities are less physically active than people without disabilities.

By age 75 , one in three men and one in two women engage in no regular physical activity.

\section{Other Issues}

The major barriers most people face when trying to increase physical activity are lack of time, lack of access to convenient facilities, and lack of safe environments in which to be active.

For more information on Healthy People 2010 objectives or on physical activity and fitness, visit http://www.health.gov/healthypeople/ or call 1-800-367-4725. 


\section{Overweight and Obesity}

\section{Leading Health Indicator}

Overweight and obesity are major contributors to many preventable causes of death. On average, higher body weights are associated with higher death rates. The number of overweight children, adolescents, and adults has risen over the past four decades. Total costs (medical cost and lost productivity) attributable to obesity alone amounted to an estimated \$99 billion in 1995.

During 1988-94, 11 percent of children and adolescents aged 6 to 19 years were overweight or obese. During the same years, 23 percent of adults aged 20 years and older were considered obese.

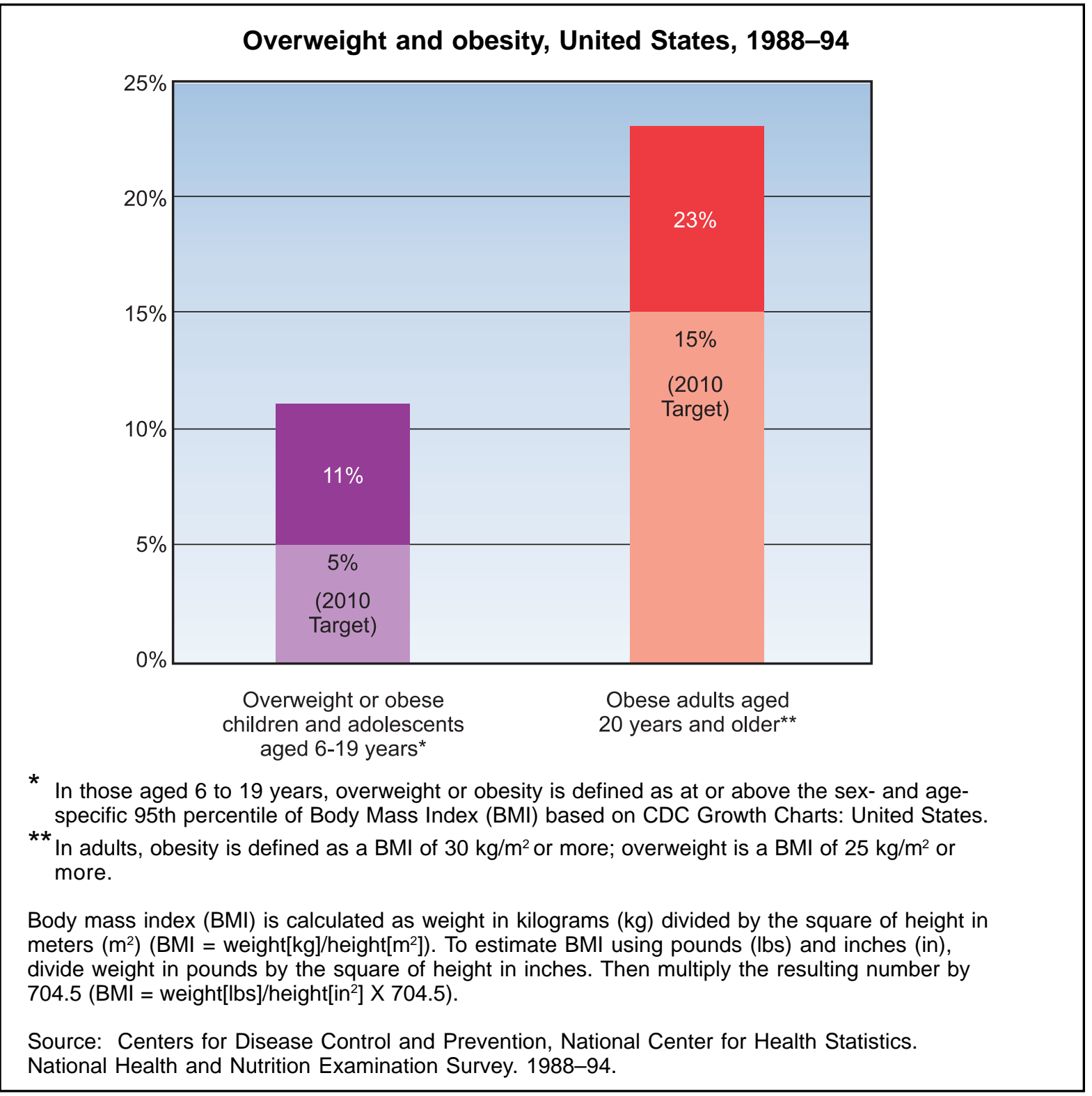

The objectives selected to measure progress among children, adolescents, and adults for this Leading Health Indicator are presented below. These are only indicators and do not represent all the nutrition and overweight objectives included in Healthy People 2010.

\section{9-3c. Reduce the proportion of children and adolescents who are overweight or obese.}

19-2. Reduce the proportion of adults who are obese. 
Leading Health Indicator

\section{Health Impact of Overweight and Obesity}

Overweight and obesity substantially raise the risk of illness from high blood pressure, high cholesterol, type 2 diabetes, heart disease and stroke, gallbladder disease, arthritis, sleep disturbances and problems breathing, and certain types of cancers. Obese individuals also may suffer from social stigmatization, discrimination, and lowered self-esteem.

\section{Populations With High Rates of Overweight and Obesity}

More than half of adults in the United States are estimated to be overweight or obese. The proportion of adolescents from poor households who are overweight or obese is twice that of adolescents from middle- and high-income households. Obesity is especially prevalent among women with lower incomes and is more common among African American and Mexican American women than among white women. Among African Americans, the proportion of women who are obese is 80 percent higher than the proportion of men who are obese. This gender difference also is seen among Mexican American women and men, but the percentage of white, non-Hispanic women and men who are obese is about the same.

\section{Reducing Overweight and Obesity}

Obesity is a result of a complex variety of social, behavioral, cultural, environmental, physiological, and genetic factors. Efforts to maintain a healthy weight should start early in childhood and continue throughout adulthood, as this is likely to be more successful than efforts to lose substantial amounts of weight and maintain weight loss once obesity is established.

A healthy diet and regular physical activity are both important for maintaining a healthy weight. Over time, even a small decrease in calories eaten and a small increase in physical activity can help prevent weight gain or facilitate weight loss. It is recommended that obese individuals who are trying to lose substantial amounts of weight seek the guidance of a health care provider.

\section{Dietary and Physical Activity Recommendations}

The Dietary Guidelines for Americans recommend that to build a healthy base, persons aged 2 years and older choose a healthful assortment of foods that includes vegetables; fruits; grains (especially whole grains); fat-free or low-fat milk products; and fish, lean meat, poultry, or beans. The guidelines further emphasize the importance of choosing foods that are low in saturated fat and added sugars most of the time and, whatever the food, eating a sensible portion size. It is recognized, however, that this guidance may be particularly challenging when eating out because the consumer may be offered large portion sizes with unknown amounts of saturated fat and added sugars.

The Dietary Guidelines for Americans recommend that all adults be more active throughout the day and get at least 30 minutes of moderate physical activity most, or preferably all, days of the week. Adults who are trying to maintain healthy weight after weight loss are advised to get even more physical activity. The guidelines also recommend that children get at least 60 minutes of physical activity daily and limit inactive forms of play such as television watching and computer games.

For more information on Healthy People 2010 objectives or on overweight and obesity, visit http://www.health.gov/healthypeople/ or call 1-800-367-4725. 


\section{Tobacco Use}

\section{Leading Health Indicator}

Cigarette smoking is the single most preventable cause of disease and death in the United States. Smoking results in more deaths each year in the United States than AIDS, alcohol, cocaine, heroin, homicide, suicide, motor vehicle crashes, and fires—combined.

Tobacco-related deaths number more than 430,000 per year among U.S. adults, representing more than 5 million years of potential life lost. Direct medical costs attributable to smoking total at least $\$ 50$ billion per year.

In 1999, 35 percent of adolescents were current cigarette smokers. In 1998, 24 percent of adults were current cigarette smokers.

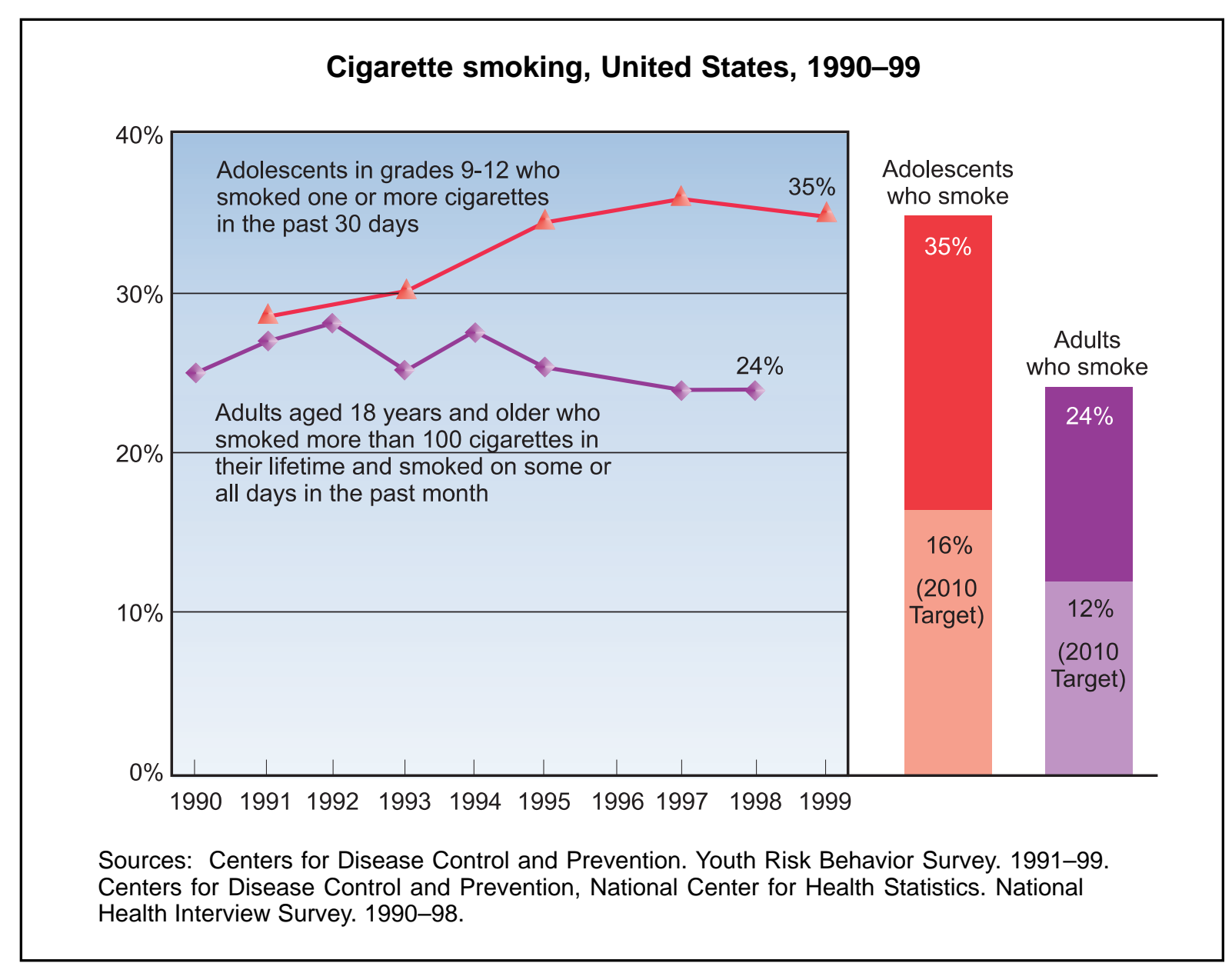

The objectives selected to measure progress among adolescents and adults for this Leading Health Indicator are presented below. These are only indicators and do not represent all the tobacco use objectives included in Healthy People 2010.

\section{7-2b. Reduce cigarette smoking by adolescents. \\ 27-1a. Reduce cigarette smoking by adults.}




\section{Health Impact of Cigarette Smoking}

Smoking is a major risk factor for heart disease, stroke, lung cancer, and chronic lung diseases-all leading causes of death. Smoking during pregnancy can result in miscarriages, premature delivery, and sudden infant death syndrome. Other health effects of smoking result from injuries and environmental damage caused by fires.

Environmental tobacco smoke (ETS) increases the risk of heart disease and significant lung conditions, especially asthma and bronchitis in children. ETS is responsible for an estimated 3,000 lung cancer deaths each year among adult nonsmokers.

\section{Trends in Cigarette Smoking}

Adolescents. Overall, the percentage of adolescents in grades 9 through 12 who smoked in the past month increased in the 1990s. Every day, an estimated 3,000 young persons start smoking. These trends are disturbing because the vast majority of adult smokers tried their first cigarette before age 18 years; more than half of adult smokers became daily smokers before this same age. Almost half of adolescents who continue smoking regularly will die eventually from a smoking-related illness.

Adults. Following years of steady decline, rates of smoking among adults appear to have leveled off in the 1990s.

\section{Populations With High Rates of Smoking}

Adolescents. Adolescent rates of cigarette smoking have increased in the 1990s among white, African American, and Hispanic high school students after years of declining rates during the 1970s and 1980s. In 1999, 39 percent of white high school students currently smoked cigarettes compared with 33 percent for Hispanics and 20 percent for African Americans. Among African Americans in 1999, only 19 percent of high school girls, compared with 22 percent of boys, currently smoked cigarettes.

Adults. Overall, American Indians and Alaska Natives, blue-collar workers, and military personnel have the highest rates of smoking in adults. Rates of smoking in Asian and Pacific Islander men are more than four times higher than for women of the same race. Men have only somewhat higher rates of smoking than women within the total U.S. population. Low-income adults are more likely to smoke than are high-income adults. The percentage of people aged 25 years and older with less than 12 years of education who are current smokers is nearly three times that for persons with 16 or more years of education.

\section{Other Important Tobacco Issues}

There is no safe tobacco alternative to cigarettes. Spit tobacco (chew) causes cancer of the mouth, inflammation of the gums, and tooth loss. Cigar smoking causes cancer of the mouth, throat, and lungs and can increase the risk of heart disease and chronic lung problems.

For more information on Healthy People 2010 objectives or on tobacco use, visit http://www.health.gov/healthypeople/ or call 1-800-367-4725. 


\section{Leading Health Indicator}

Alcohol and illicit drug use are associated with many of this country's most serious problems, including violence, injury, and HIV infection. The annual economic costs to the United States from alcohol abuse were estimated to be $\$ 167$ billion in 1995 , and the costs from drug abuse were estimated to be \$110billion.

In 1998, 79 percent of adolescents aged 12 to 17 years reported that they did not use alcohol or illicit drugs in the past month. In the same year, 6 percent of adults aged 18 years and older reported using illicit drugs in the past month; 17 percent reported binge drinking in the past month, which is defined as consuming five or more drinks on one occasion.

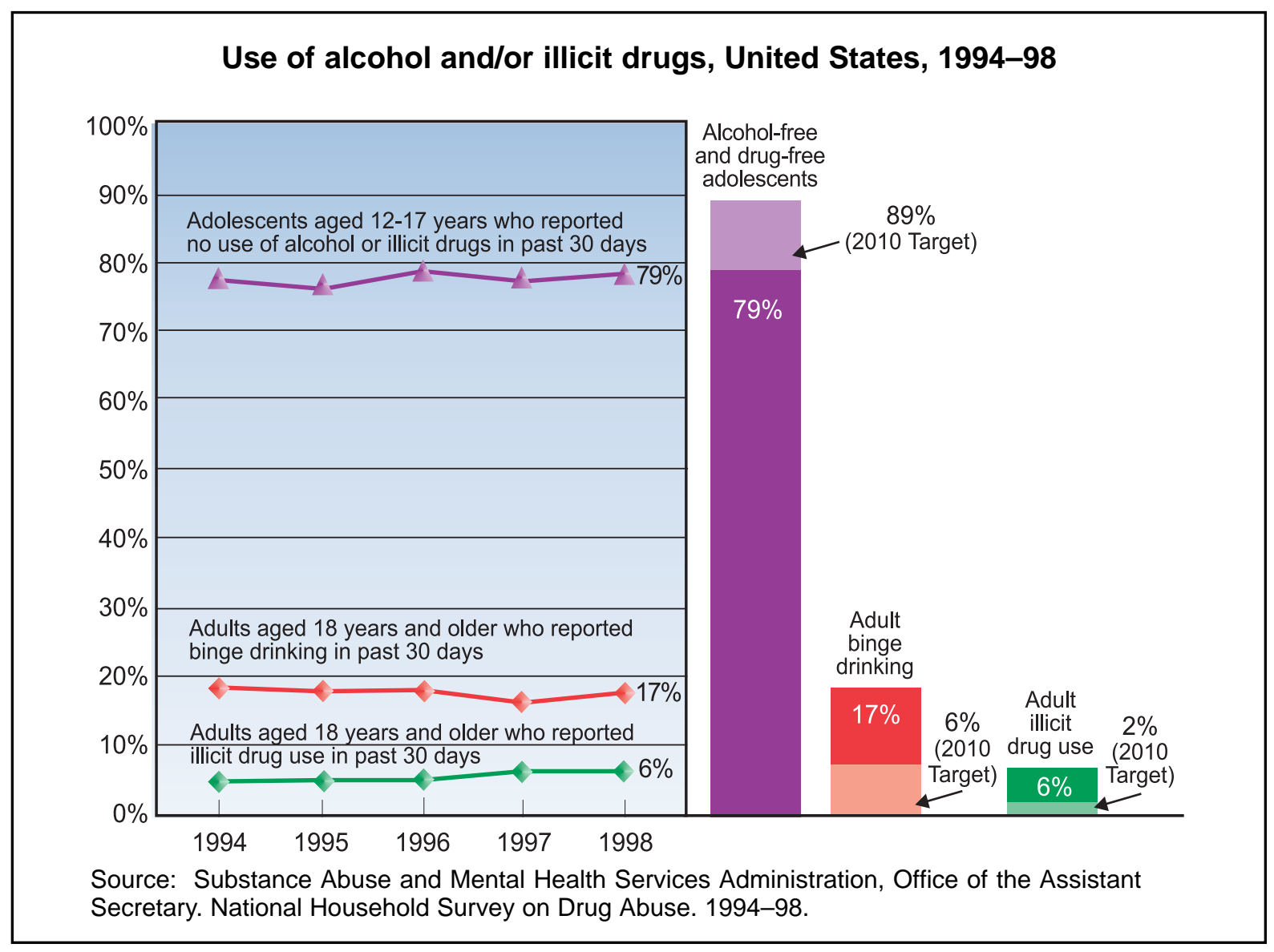

The objectives selected to measure progress among adolescents and adults for this Leading Health Indicator are presented below. These are only indicators and do not represent all the substance abuse objectives in Healthy People 2010.

26-10a. Increase the proportion of adolescents not using alcohol or any illicit drugs during the past 30 days.

26-10c. Reduce the proportion of adults using any illicit drug during the past 30 days.

26-11c. Reduce the proportion of adults engaging in binge drinking of alcoholic beverages during the past month. 


\section{Health Impact of Substance Abuse}

Alcohol and illicit drug use are associated with child and spousal abuse; sexually transmitted diseases, including HIV infection; teen pregnancy; school failure; motor vehicle crashes; escalation of health care costs; low worker productivity; and homelessness. Alcohol and illicit drug use also can result in substantial disruptions in family, work, and personal life.

Alcohol abuse alone is associated with motor vehicle crashes, homicides, suicides, and drowningleading causes of death among youth. Long-term heavy drinking can lead to heart disease, cancer, alcohol-related liver disease, and pancreatitis. Alcohol use during pregnancy is known to cause fetal alcohol syndrome, a leading cause of preventable mental retardation.

\section{Trends in Substance Abuse}

Adolescents. Although the trend from 1994 to 1998 has shown some fluctuations, about 77 percent of adolescents aged 12 to 17 years report being both alcohol-free and drug-free in the past month.

Alcohol is the drug most frequently used by adolescents aged 12 to 17 years. In 1998, 19 percent of adolescents aged 12 to 17 years reported drinking alcohol in the past month. Alcohol use in the past month for this age group has remained at about 20 percent since 1992. Eight percent of this age group reported binge drinking, and 3 percent were heavy drinkers (five or more drinks on the same occasion on each of 5 or more days in the past 30 days).

Data from 1998 show that 10 percent of adolescents aged 12 to 17 years reported using illicit drugs in the past 30 days. This rate remains well below the all-time high of 16 percent in 1979. Current illicit drug use had nearly doubled for those aged 12 to 13 years between 1996 and 1997 but then decreased between 1997 and 1998. Youth are experimenting with a variety of illicit drugs, including marijuana, cocaine, crack, heroin, acid, inhalants, and methamphetamines, as well as misuse of prescription drugs and other "street" drugs. The younger a person becomes a habitual user of illicit drugs, the stronger the addiction becomes and the more difficult it is to stop use.

Adults. Binge drinking has remained at the same approximate level of 17 percent for all adults since 1988, with the highest current rate of 32 percent among adults aged 18 to 25 years. Illicit drug use has been near the present rate of 6 percent since 1980. Men continue to have higher rates of illicit drug use than women have, and rates of illicit drug use in urban areas are higher than in rural areas.

For more information on Healthy People 2010 objectives or on substance abuse, visit http://www.health.gov/healthypeople/ or call 1-800-367-4725. 


\section{Responsible Sexual Behavior}

\section{Leading Health Indicator}

Unintended pregnancies and sexually transmitted diseases (STDs), including infection with the human immunodeficiency virus that causes AIDS, can result from unprotected sexual behaviors. Abstinence is the only method of complete protection. Condoms, if used correctly and consistently, can help prevent both unintended pregnancy and STDs.

In 1999, 85 percent of adolescents abstained from sexual intercourse or used condoms if they were sexually active. In 1995, 23 percent of sexually active women reported that their partners used condoms.

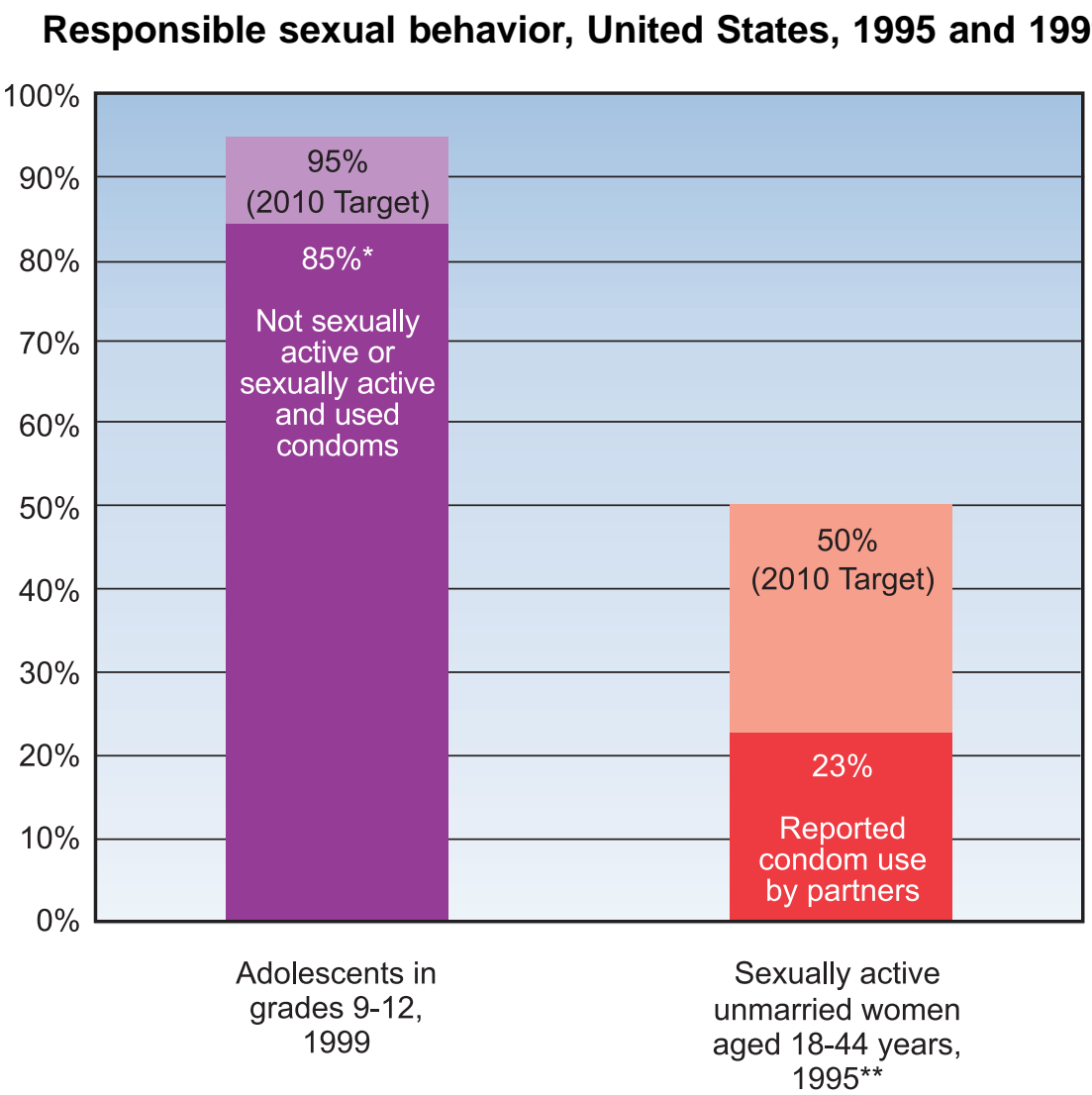

* This 85 percent includes 50 percent of students in grades 9-12 who were not ever sexually active, 14 percent who were not sexually active in the past 3 months, and 21 percent who were sexually active but used a condom at the last intercourse.

** Data on males aged 15 to 49 years will be collected in 2003.

Sources: Centers for Disease Control and Prevention. Youth Risk Behavior Survey. 1999. Centers for Disease Control and Prevention, National Center for Health Statistics. National Survey of Family Growth. 1995.

The objectives selected to measure progress among adolescents and adults for this Leading Health Indicator are presented below. These are only indicators and do not represent all the responsible sexual behavior objectives in Healthy People 2010.

\section{5-11. Increase the proportion of adolescents who abstain from sexual intercourse or use condoms if currently sexually active.}

13-6a. Increase the proportion of sexually active persons who use condoms. 


\section{Trends in Sexual Behavior}

In the past 6 years there has been both an increase in abstinence among all youth and an increase in condom use among those young people who are sexually active. Research has shown clearly that the most effective school-based programs are comprehensive ones that include a focus on abstinence and condom use. Condom use in sexually active adults has remained steady at about 25 percent.

\section{Unintended Pregnancies}

Half of all pregnancies in the United States are unintended; that is, at the time of conception the pregnancy was not planned or not wanted. Unintended pregnancy rates in the United States have been declining. The rates remain highest among teenagers, women aged 40 years or older, and lowincome African American women. Approximately 1 million teenage girls each year in the United States have unintended pregnancies. Nearly half of all unintended pregnancies end in abortion.

The cost to U.S. taxpayers for adolescent pregnancy is estimated at between $\$ 7$ billion and $\$ 15$ billion a year.

\section{Sexually Transmitted Diseases}

Sexually transmitted diseases are common in the United States, with an estimated 15 million new cases of STDs reported each year. Almost 4 million of the new cases of STDs each year occur in adolescents. Women generally suffer more serious STD complications than men, including pelvic inflammatory disease, ectopic pregnancy, infertility, chronic pelvic pain, and cervical cancer from the human papilloma virus. African Americans and Hispanics have higher rates of STDs than whites.

The total cost of the most common STDs and their complications is conservatively estimated at $\$ 17$ billion annually.

\section{HIV/AIDS}

Nearly 700,000 cases of AIDS have been reported in the United States since the HIV/AIDS epidemic began in the 1980s. The latest estimates indicate that 800,000 to 900,000 people in the United States currently are infected with HIV. The lifetime cost of health care associated with HIV infection, in light of recent advances in HIV diagnostics and therapies, is $\$ 155,000$ or more per person.

About one-half of all new HIV infections in the United States are among people under age 25 years, and the majority are infected through sexual behavior. HIV infection is the leading cause of death for African American men aged 25 to 44 years. Compelling worldwide evidence indicates that the presence of other STDs increases the likelihood of both transmitting and acquiring HIV infection.

For more information on Healthy People 2010 objectives or on responsible sexual behavior, visit http://www.health.gov/healthypeople/ or call 1-800-367-4725. 


\section{Leading Health Indicator}

Approximately 20 percent of the U.S. population is affected by mental illness during a given year; no one is immune. Of all mental illnesses, depression is the most common disorder. More than 19 million adults in the United States suffer from depression. Major depression is the leading cause of disability and is the cause of more than two-thirds of suicides each year.

In 1997, only 23 percent of adults diagnosed with depression received treatment.

\section{Adults with depression* who received treatment, ${ }^{\star *}$ United States, 1994-97}

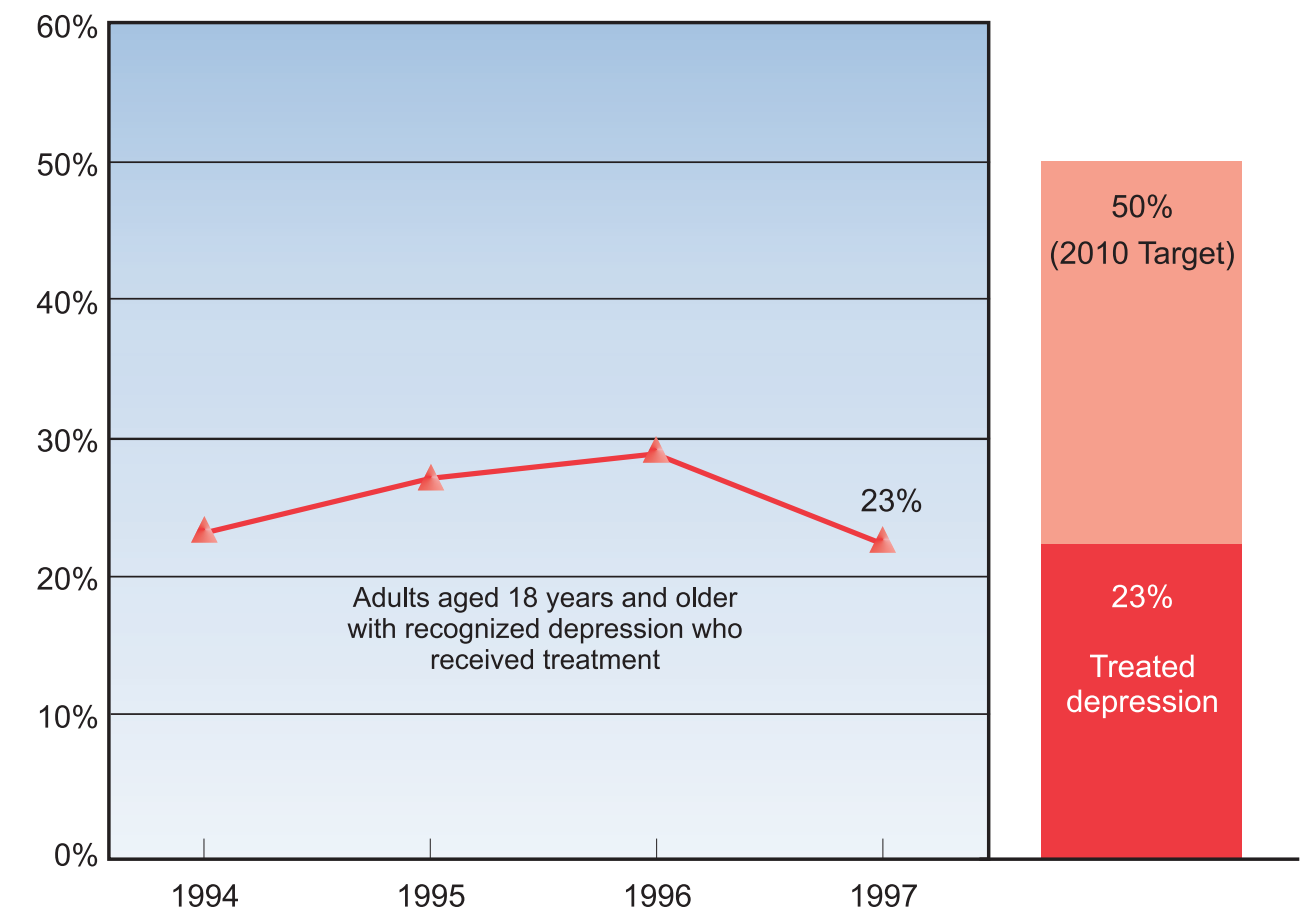

* Depression is defined as major depressive episode in the past year.

** Treatment is defined as treatment in the past year for psychological problems or emotional difficulties at a mental health clinic or by a mental health professional on an outpatient basis or treatment for psychological or emotional difficulties at a hospital overnight or longer.

Source: Substance Abuse and Mental Health Services Administration, Office of Applied Studies. National Household Survey on Drug Abuse. 1994-97.

The objective selected to measure progress among adults for this Leading Health Indicator is presented below. This is only an indicator and does not represent all the mental health objectives in Healthy People 2010.

18-9b. Increase the proportion of adults with recognized depression who receive treatment. 


\section{Definition of Mental Health}

Mental health is sometimes thought of as simply the absence of a mental illness but is actually much broader. Mental health is a state of successful mental functioning, resulting in productive activities, fulfilling relationships, and the ability to adapt to change and cope with adversity. Mental health is indispensable to personal well-being, family and interpersonal relationships, and one's contribution to society.

\section{Impact of Depression}

A person with a depressive disorder often is unable to fulfill the daily responsibilities of being a spouse, partner, or parent. The misunderstanding of mental illness and the associated stigmatization prevent many persons with depression from seeking professional help. Many people will be incapacitated for weeks or months because their depression goes untreated.

Depression is associated with other medical conditions, such as heart disease, cancer, and diabetes as well as anxiety and eating disorders. Depression also has been associated with alcohol and illicit drug abuse. An estimated 8 million persons aged 15 to 54 years had coexisting mental and substance abuse disorders within the past year.

The total estimated direct and indirect cost of mental illness in the United States in 1996 was \$150 billion.

\section{Treatment of Depression}

Depression is treatable. Available medications and psychological treatments, alone or in combination, can help 80 percent of those with depression. With adequate treatment, future episodes of depression can be prevented or reduced in severity. Treatment for depression can enable people to return to satisfactory, functioning lives.

\section{Populations With High Rates of Depression}

Serious mental illness clearly affects mental health and can affect children, adolescents, adults, and older adults of all ethnic and racial groups, both genders, and people at all educational and income levels.

Adults and older adults have the highest rates of depression. Major depression affects approximately twice as many women as men. Women who are poor, on welfare, less educated, unemployed, and from certain racial or ethnic populations are more likely to experience depression. In addition, depression rates are higher among older adults with coexisting medical conditions. For example, 12 percent of older persons hospitalized for problems such as hip fracture or heart disease are diagnosed with depression. Rates of depression for older persons in nursing homes range from 15 to 25 percent.

For more information on Healthy People 2010 objectives or on mental health, visit http://www.health.gov/healthypeople/ or call 1-800-367-4725. 


\section{Injury and Violence}

\section{Leading Health Indicator}

More than 400 Americans die each day from injuries due primarily to motor vehicle crashes, firearms, poisonings, suffocation, falls, fires, and drowning. The risk of injury is so great that most persons sustain a significant injury at some time during their lives.

Motor vehicle crashes are the most common cause of serious injury. In 1998, there were 15.6 deaths from motor vehicle crashes per 100,000 persons.

Because no other crime is measured as accurately and precisely, homicide is a reliable indicator of all violent crime. In 1998, the murder rate in the United States fell to its lowest level in three decades6.5 homicides per 100,000 persons.

\section{Motor vehicle deaths and homicides, United States, 1998}

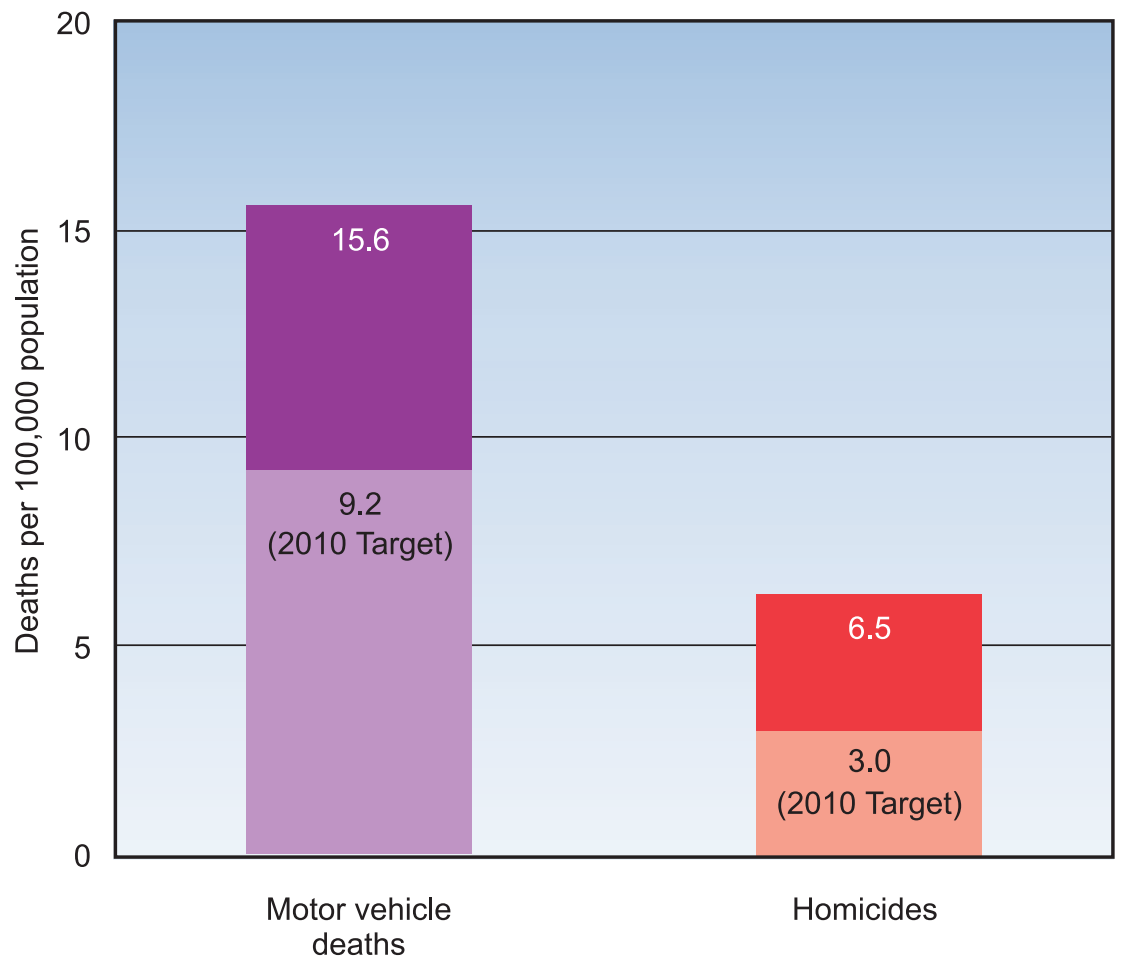

Source: Centers for Disease Control and Prevention, National Center for Health Statistics. National Vital Statistics System. 1998.

The objectives selected to measure progress for this Leading Health Indicator are presented below. These are only indicators and do not represent all the injury and violence prevention objectives in Healthy People 2010.

15-15a. Reduce deaths caused by motor vehicle crashes.

15-32. Reduce homicides. 


\section{Impact of Injury and Violence}

In 1995, the cost of injury and violence in the United States was estimated at more than $\$ 224$ billion per year. These costs include direct medical care and rehabilitation as well as productivity losses to the Nation's workforce. The total societal cost of motor vehicle crashes alone exceeds $\$ 150$ billion annually.

\section{Motor Vehicle Crashes}

Motor vehicle crashes often are predictable and preventable. Increased use of safety belts and reductions in driving while impaired are two of the most effective means to reduce the risk of death and serious injury of occupants in motor vehicle crashes.

Death rates associated with motor vehicle-traffic injuries are highest in the age group 15 to 24 years. In 1996, teenagers accounted for only 10 percent of the U.S. population but 15 percent of the deaths from motor vehicle crashes. Those aged 75 years and older had the second highest rate of motor vehicle-related deaths.

Nearly 40 percent of traffic fatalities in 1997 were alcohol related. Each year in the United States it is estimated that more than 120 million episodes of impaired driving occur among adults. In 1996, 21 percent of traffic fatalities of children aged 14 years and under involved alcohol; 60 percent of the time the driver of the car in which the child was a passenger was impaired.

The highest intoxication rates in fatal crashes in 1995 were recorded for drivers aged 21 to 24 years. Young drivers who have been arrested for driving while impaired are more than four times as likely to die in future alcohol-related crashes.

\section{Homicides}

In 1997, 32,436 individuals died from firearm injuries; of this number, 42 percent were victims of homicide. In 1997, homicide was the third leading cause of death for children aged 5 to 14 years, an increasing trend in childhood violent deaths. In 1996, more than 80 percent of infant homicides were considered to be fatal child abuse.

Many factors that contribute to injuries are also closely associated with violent and abusive behavior, such as low income, discrimination, lack of education, and lack of employment opportunities.

Males are most often the victims and the perpetrators of homicides. African Americans are more than five times as likely as whites to be murdered. There has been a decline in the homicide of intimates, including spouses, partners, boyfriends, and girlfriends, over the past decade, but this problem remains significant.

For more information on Healthy People 2010 objectives or on injury and violence, visit http://www.health.gov/healthypeople/ or call 1-800-367-4725. 


\section{Environmental Quality}

\section{Leading Health Indicator}

An estimated 25 percent of preventable illnesses worldwide can be attributed to poor environmental quality. In the United States, air pollution alone is estimated to be associated with 50,000 premature deaths and an estimated $\$ 40$ billion to $\$ 50$ billion in health-related costs annually. Two indicators of air quality are ozone (outdoor) and environmental tobacco smoke (indoor).

In 1997, approximately 43 percent of the U.S. population lived in areas designated as nonattainment areas for established health-based standards for ozone. During the years 1988 to 1994, 65 percent of nonsmokers were exposed to environmental tobacco smoke (ETS).

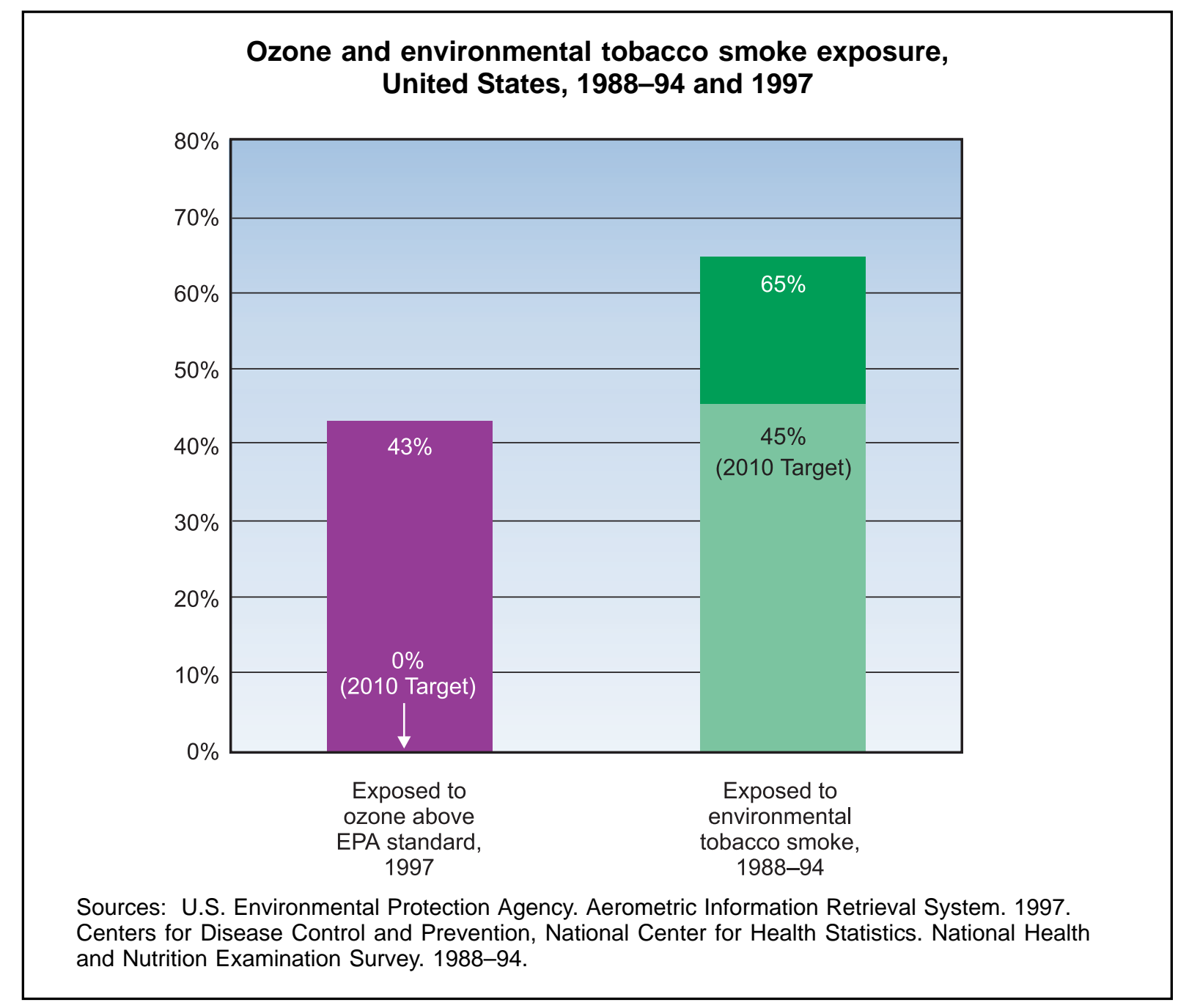

The objectives selected to measure progress among children, adolescents, and adults for this Leading Health Indicator are presented below. These are only indicators and do not represent all the environmental quality objectives in Healthy People 2010.

\section{8-1a. Reduce the proportion of persons exposed to air that does not meet the} U.S. Environmental Protection Agency's health-based standards for ozone.

27-10. Reduce the proportion of nonsmokers exposed to environmental tobacco smoke. 


\section{Defining the Environment}

Physical and social environments play major roles in the health of individuals and communities. The physical environment includes the air, water, and soil through which exposure to chemical, biological, and physical agents may occur. The social environment includes housing, transportation, urban development, land use, industry, and agriculture and results in exposures such as work-related stress, injury, and violence.

\section{Global Concern}

Environmental quality is a global concern. Ever-increasing numbers of people and products cross national borders and may transfer health risks such as infectious diseases and chemical hazards. For example, pesticides that are not registered or are restricted for use in the United States potentially could be imported in the fruits, vegetables, and seafood produced abroad.

\section{Health Impact of Poor Air Quality}

Poor air quality contributes to respiratory illness, cardiovascular disease, and cancer. For example, asthma can be triggered or worsened by exposure to ozone and ETS. The overall death rate from asthma increased 57 percent between 1980 and 1993, and for children it increased 67 percent.

Air Pollution. Dramatic improvements in air quality in the United States have occurred over the past three decades. Between 1970 and 1997, total emissions of the six principal air pollutants decreased 31 percent. Still, millions of tons of toxic pollutants are released into the air each year from automobiles, industry, and other sources. In 1997, despite continued improvements in air quality, approximately 120 million people lived in areas with unhealthy air based on established standards for one or more commonly found air pollutants, including ozone. In 1996, a disproportionate number of Hispanics and Asian and Pacific Islanders lived in areas that failed to meet these standards compared with whites, African Americans, and American Indians or Alaska Natives.

Tobacco Smoke. Exposure to ETS, or secondhand smoke, among nonsmokers is widespread. Home and workplace environments are major sources of exposure. A total of 15 million children are estimated to have been exposed to secondhand smoke in their homes in 1996. ETS increases the risk of heart disease and respiratory infections in children and is responsible for an estimated 3,000 cancer deaths of adult nonsmokers.

\section{Improvement in Environmental Quality}

In the United States, ensuring clean water, safe food, and effective waste management has contributed greatly to a declining threat from many infectious diseases; however, there is still more that can be done. Work to improve the air quality and to understand better threats such as chronic, low-level exposures to hazardous substances also must continue.

For more information on Healthy People 2010 objectives or on environmental quality, visit http://www.health.gov/healthypeople/ or call 1-800-367-4725. 


\section{Immunization}

\section{Leading Health Indicator}

Vaccines are among the greatest public health achievements of the 20th century. Immunizations can prevent disability and death from infectious diseases for individuals and can help control the spread of infections within communities.

In 1998, 73 percent of children received all vaccines recommended for universal administration.

In 1998, influenza immunization rates were 64 percent in adults aged 65 years and older-almost double the 1989 immunization rate of 33 percent. In 1998, only 46 percent of persons aged 65 years and older had ever received a pneumococcal vaccine.

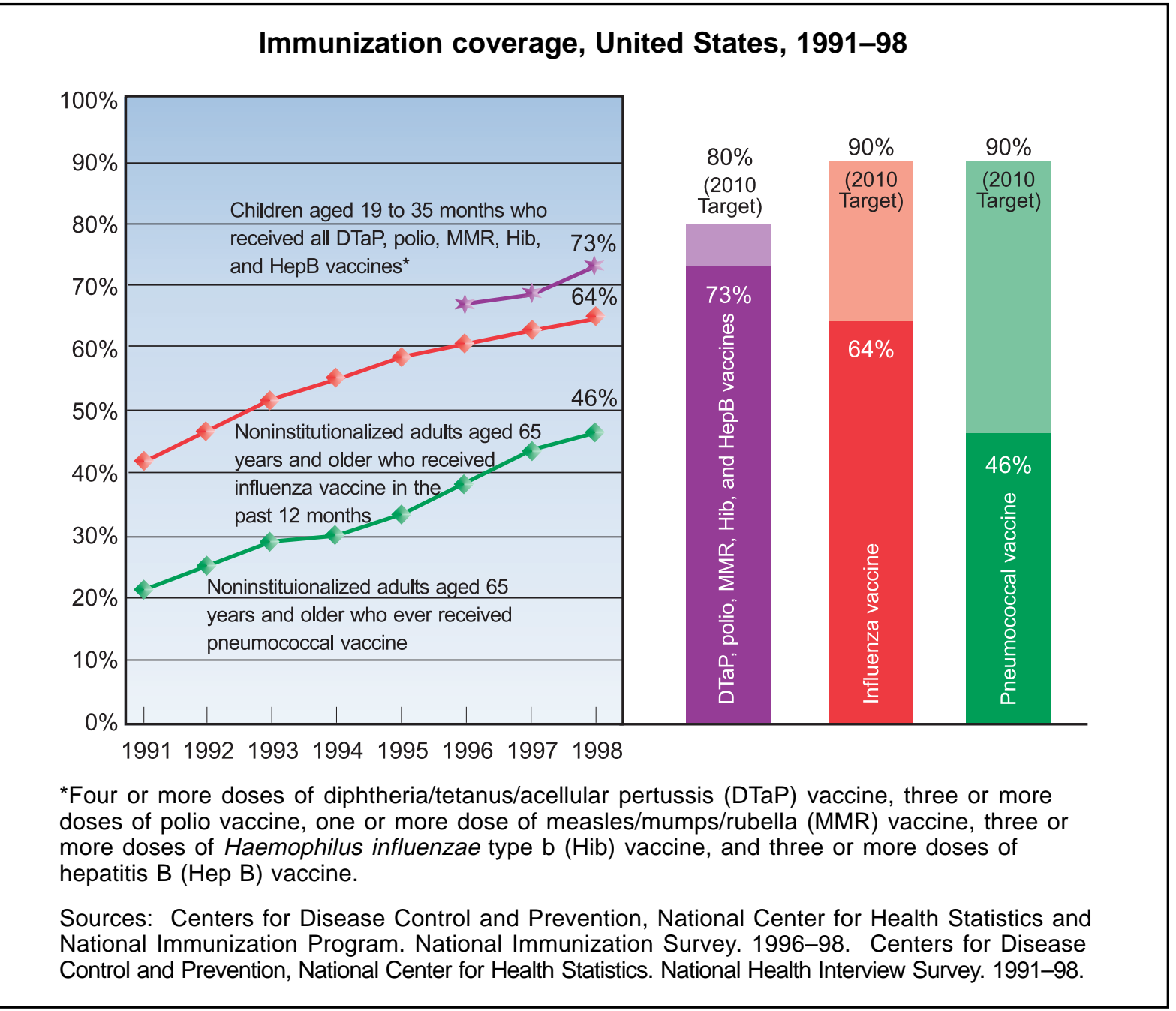

The objectives selected to measure progress among children and adults for this Leading Health Indicator are presented below. These are only indicators and do not represent all the immunization and infectious diseases objectives in Healthy People 2010.

14-24a. Increase the proportion of young children who receive all vaccines that have been recommended for universal administration for at least 5 years.

14-29a, b. Increase the proportion of noninstitutionalized adults who are vaccinated annually against influenza and ever vaccinated against pneumococcal disease. 


\section{Impact of Immunization}

Many once-common vaccine-preventable diseases now are controlled. Smallpox has been eradicated, poliomyelitis has been eliminated from the Western Hemisphere, and measles cases in the United States are at a record low.

Immunizations against influenza and pneumococcal disease can prevent serious illness and death. Pneumonia and influenza deaths together constitute the sixth leading cause of death in the United States. Influenza causes an average of 110,000 hospitalizations and 20,000 deaths annually; pneumococcal disease causes 10,000 to 14,000 deaths annually.

\section{Recommended Immunizations}

As of November 1, 1999, all children born in the United States (11,000 per day) should be receiving 12 to 16 doses of vaccine by age 2 years to be protected against 10 vaccine-preventable childhood diseases. This recommendation will change in the years ahead as new vaccines are developed, including combinations of current vaccines that may even reduce the number of necessary shots.

Recommended immunizations for adults aged 65 years and older include a yearly immunization against influenza (the "flu shot") and a one-time immunization against pneumococcal disease. Most of the deaths and serious illnesses caused by influenza and pneumococcal disease occur in older adults and others at increased risk for complications of these diseases because of other risk factors or medical conditions.

\section{Trends in Immunization}

National coverage levels in children now are greater than 90 percent for each immunization recommended during the first 2 years of life, except for hepatitis $B$ and varicella vaccines. The hepatitis B immunization rate in children was 87 percent in 1998 - the highest level ever reported. In 1998, 70 percent of children aged 19 to 35 months from the lowest income households received the combined series of recommended immunizations, compared with 77 percent of children from higher income households.

Both influenza and pneumococcal immunization rates are significantly lower for African American and Hispanic adults than for white adults.

\section{Other Immunization Issues}

Coverage levels for immunizations in adults are not as high as those achieved in children, yet the health effects may be just as great. Barriers to adult immunization include not knowing immunizations are needed, misconceptions about vaccines, and lack of recommendations from health care providers.

For more information on Healthy People 2010 objectives or on immunization and infectious diseases, visit http://www.health.gov/healthypeople/ or call 1-800-367-4725. 


\section{Leading Health Indicator}

Strong predictors of access to quality health care include having health insurance, a higher income level, and a regular primary care provider or other source of ongoing health care. Use of clinical preventive services, such as early prenatal care, can serve as indicators of access to quality health care services.

In 1997, 83 percent of persons under age 65 years had health insurance. In 1998, 87 percent of persons of all ages had a usual source of health care. Also in that year, 83 percent of pregnant women received prenatal care in the first trimester of pregnancy.

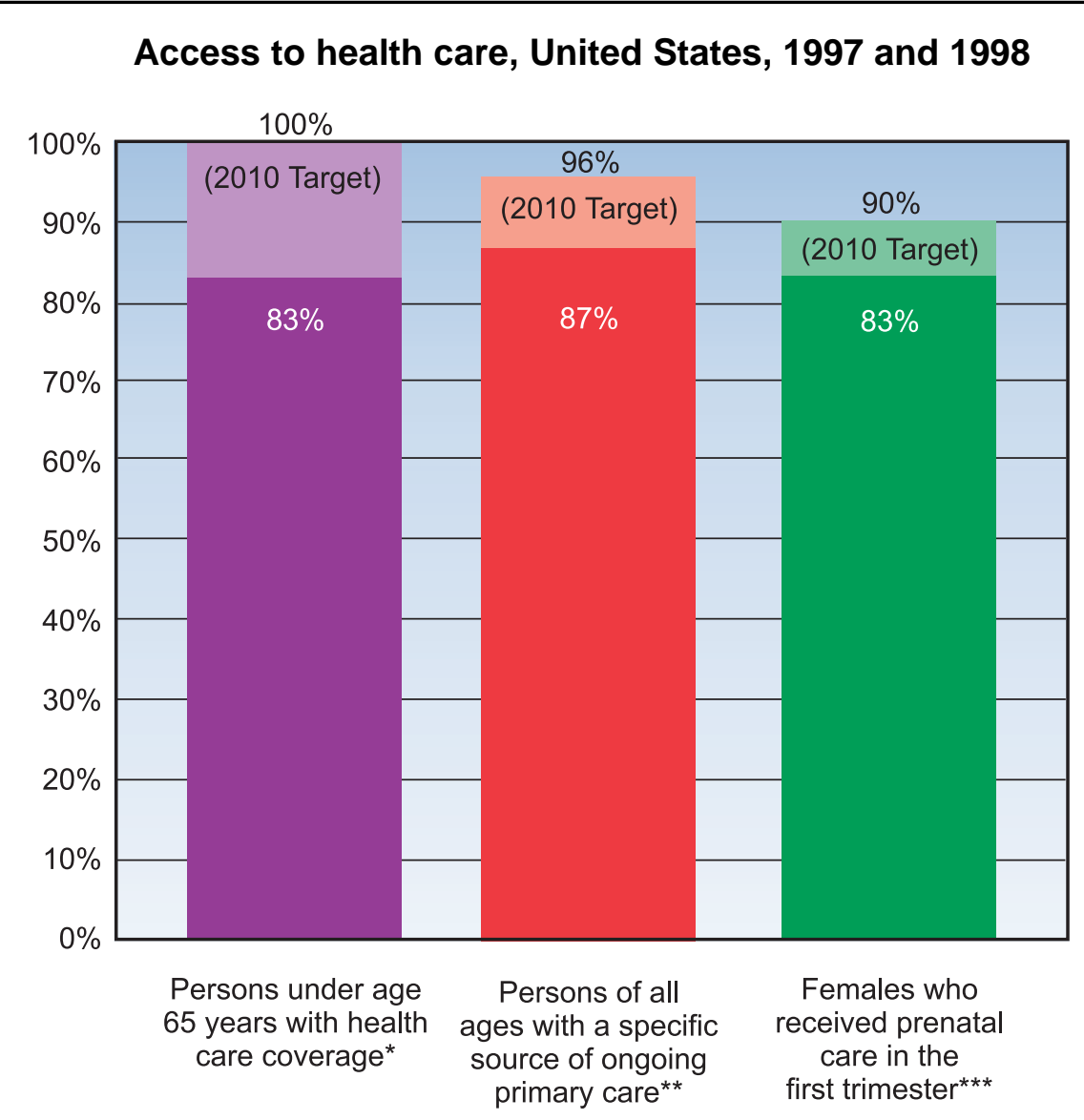

Sources: Centers for Disease Control and Prevention, National Center for Health Statistics. National Health Interview Survey. *1997 and ${ }^{* *} 1998$. Centers for Disease Control and Prevention, National Center for Health Statistics. National Vital Statistics System. ${ }^{* *} 1998$.

The objectives selected to measure progress for this Leading Health Indicator are presented below. These are only indicators and do not represent all the access to quality health services objectives in Healthy People 2010.

1-1. Increase the proportion of persons with health insurance.

1-4a. Increase the proportion of persons who have a specific source of ongoing care.

16-6a. Increase the proportion of pregnant women who begin prenatal care in the first trimester of pregnancy. 


\section{Health Insurance}

Health insurance provides access to health care. Persons with health insurance are more likely to have a primary care provider and to have received appropriate preventive care such as a recent Pap test, immunization, or early prenatal care. Adults with health insurance are twice as likely to receive a routine checkup as are adults without health insurance.

More than 44 million persons in the United States do not have health insurance, including 11 million uninsured children. Over the past decade, the proportion of persons under age 65 years with health insurance remained steady at about 85 percent. About one-third of adults under age 65 years below the poverty level were uninsured. For persons of Hispanic origin, approximately one in three was without health insurance coverage in 1997. Mexican Americans had one of the highest uninsured rates at 40 percent.

\section{Ongoing Sources of Primary Care}

More than 40 million Americans do not have a particular doctor's office, clinic, health center, or other place where they usually go to seek health care or health-related advice. Even among privately insured persons, a significant number lacked a usual source of care or reported difficulty in accessing needed care due to financial constraints or insurance problems.

People aged 18 to 24 years were the most likely to lack a usual source of ongoing primary care. Only 80 percent of individuals below the poverty level and 79 percent of Hispanics had a usual source of ongoing primary care.

\section{Barriers to Access}

Financial, structural, and personal barriers can limit access to health care. Financial barriers include not having health insurance, not having enough health insurance to cover needed services, or not having the financial capacity to cover services outside a health plan or insurance program. Structural barriers include the lack of primary care providers, medical specialists, or other health care professionals to meet special needs or the lack of health care facilities. Personal barriers include cultural or spiritual differences, language barriers, not knowing what to do or when to seek care, or concerns about confidentiality or discrimination.

For more information on Healthy People 2010 objectives or on access to health care, visit http://www.health.gov/healthypeople/ or call 1-800-367-4725. 



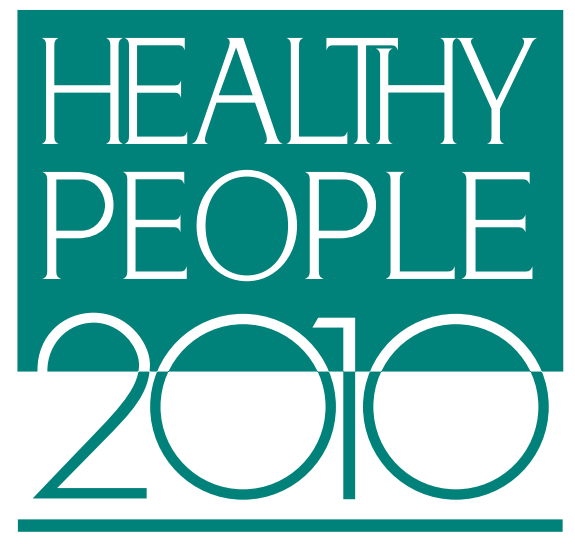

\section{Bibliography}

\section{Introduction}

McGinnis, J.M., and Maiese, D.R. Defining mission, goals, and objectives. In: Scutchfield, F.D., and Keck, C.W., eds. Principles of Public Health Practice. Albany, NY: Delmar Publishers, 1997, 140-141.

\section{A Systematic Approach to Health Improvement}

\section{Goals}

American College of Physicians. Rural primary care. Annals of Internal Medicine 122(5):380-390, 1995.

American Medical Association Council Report. Health care needs of gay men and lesbians in the United States. Journal of the American Medical Association 247:13541359, 1996.

Centers for Disease Control and Prevention (CDC).

Behavioral Risk Factor Surveillance System Prevalence Data, 1998. <http://ww2.cdc.gov/nccdphp/brfss/ index.asp>.

CDC. Health-related quality of life and activity limitation-eight states, 1995. Morbidity and Mortality Weekly Report 47(7):134-140, 1998.

CDC. Health-related quality-of-life measures-United States, 1993. Morbidity and Mortality Weekly Report 44:195-200, 1995.

U.S. Department of Health and Human Services (HHS). Terminology, Focus Area 6. Disability and Secondary Conditions. Healthy People 2010. 2nd ed. Vol. I. Washington, DC: U.S. Government Printing Office (GPO), November 2000, 24-25.
Institute of Medicine (IOM). Improving Health in the Community. Washington, DC: National Academy Press, 1997, 48-56.

National Center for Health Statistics (NCHS). Health, United States, 1999. With health and aging chartbook. Hyattsville, MD: HHS, 1999.

NCHS. Healthy People 2000 Review, 1998-99. Hyattsville, MD: HHS, 1999.

Barker, W.H. Prevention of disability in older persons. In: Wallace, R.B., ed. Public Health and Preventive Medicine.14th ed. Stamford, CT: Appleton \& Lange, 1998, 1063.

Braden, J., and Beauregard, K. Health Status and Access to Care of Rural and Urban Populations. AHCPR Pub. No. 94-0031. Rockville, MD: Public Health Service (PHS), Agency for Health Care Policy and Research (AHCPR), 1994.

Catalan, J., and Pugh, K. Suicidal behaviour and HIV infection-is there a link? AIDS Care 7(Suppl. 2):S117S121, 1995.

Cochran, S.D., and Mays, V.M. Depressive distress among homosexually active African American men and women. American Journal of Psychiatry 151:524-529, 1994.

Davidson, L., and Linnoila, M., eds. Report of the Secretary's Task Force on Youth Suicide, 2: Risk Factors for Youth Suicide. Washington, DC: HHS, PHS, 1989.

Frumkin, H., and Walker, E.D. Minority workers and communities. In: Wallace, R.B., ed. Public Health and Preventive Medicine. 14th ed. Stamford, CT: Appleton \& Lange, 1998, 685. 
Hoyert, D.L.; Kochanek, K.D.; and Murphy, S.L. Deaths: Final data for 1997. National Vital Statistics Reports 47(19):1999.

Idler, E.L., and Benyamini, Y. Self-rated health and mortality: A review of twenty-seven community studies. Journal of Health and Social Behavior 38:21-37, 1997.

LaPlante, M.P.; Rice, D.P.; and Cyril, J. Health insurance coverage of people with disabilities in the U.S. Disability Statistics Abstract. Disability Statistics Rehabilitation. San Francisco, CA: Research and Training Center, 1994.

Last, J.M. The determinants of health. In: Scutchfield, F.D., and Keck, C.W., eds. Principles of Public Health Practice. Albany, NY: Delmar Publishers, 1997, 33-34.

Luepker, R.V. Heart disease. In: Wallace, R.B., ed. Public Health and Preventive Medicine. 14th ed. Stamford, CT: Appleton \& Lange, 1998, 939-940.

McNeil, J.M. Americans with disabilities: 1994-95. Current Population Reports. Bureau of the Census (P70-61). Washington, DC: U.S. Department of Commerce, 1997.

Pamuk, E.; Makuc, D.; Heck, K.; et al. Socioeconomic Status and Health Chartbook. Health, United States, 1998. Hyattsville, MD: NCHS, 1998.

Pearson, T.A., and Lewis, C. Rural epidemiology: Insights from a rural population laboratory. American Journal of Epidemiology 148(10):949-957, 1998.

Solarz, A., ed. Lesbian Health: Current Assessment and Directions for the Future. Washington, DC: IOM, 1997.

Syme, S.L., and Balfour, J.L. Social determinants of disease. In: Wallace, R.B., ed. Public Health and Preventive Medicine. 14th ed. Stamford, CT: Appleton \& Lange, 1998, 800-801.

Tissue, T. Another look at self-rated health among the elderly. Journal of Gerontology 27:91-94, 1972.

Vistnes, J.P., and Monheit, A.C. Health Insurance Status of the Civilian Noninstitutionalized Population. AHCPR Pub. No. 97-0030. Rockville, MD: AHCPR, 1997.

\section{Determinants of Health}

IOM. Improving Health in the Community. Washington, DC: National Academy Press, 1997, 48-56.

McGinnis, J.M., and Maiese, D.R. Defining mission, goals, and objectives. In: Scutchfield, F.D., and Keck, C.W., eds. Principles of Public Health Practice. Albany, NY: Delmar Publishers, 1997, 136-145.

Syme, S.L., and Balfour, J.L. Social determinants of disease. In: Wallace, R.B., ed. Public Health and Preventive Medicine. 14th ed. Stamford, CT: Appleton \& Lange, 1998, 795.

\section{Health Status}

NCHS. Health, United States, 1999. With health and aging chartbook. Hyattsville, MD: HHS, 1999.

McGinnis, J.M., and Foege, W.H. Actual causes of death in the United States. Journal of the American Medical Association 270:2207-2212, 1993.

\section{Physical Activity}

CDC. Physical activity and the prevention of coronary heart disease. Morbidity and Mortality Weekly Review 42:669-672, 1993.

CDC. Prevalence of sedentary leisure-time behavior among adults in the United States. Health E-Stats. Atlanta, GA: CDC, NCHS, 1999.

NCHS. Health, United States, 1999. With health and aging chartbook. Hyattsville, MD: HHS, 1999.

NCHS. Healthy People 2000 Review, 1998-99. Hyattsville, MD: HHS, 1999.

HHS. Physical Activity and Health: A Report of the Surgeon General. Atlanta, GA: CDC, National Center for Chronic Disease Prevention and Health Promotion (NCCDPHP), 1996.

Pamuk, E.; Makuc, D.; Heck, K.; et al. Socioeconomic Status and Health Chartbook. Health, United States, 1998. Hyattsville, MD: NCHS, 1998. 


\section{Overweight and Obesity}

Agricultural Research Service. Research News. Press release, U.S. Department of Agriculture (USDA), Washington, DC, November 20, 1996.

NCHS. Health, United States, 1999. With health and aging chartbook. Hyattsville, MD: HHS, 1999.

NCHS. Healthy People 2000 Review, 1998-99. Hyattsville, MD: HHS, 1999.

National Institutes of Health (NIH). Statistics Related to Overweight and Obesity. NIH Publication No. 96-4158.

Bethesda, MD: HHS, National Institute of Diabetes and Digestive and Kidney Diseases, 1996.

USDA and HHS. Dietary Guidelines for Americans. 4th ed. USDA Home and Garden Bulletin No. 232. December 1995.

Lin, B.H., and Frazao, E. Nutritional quality of foods at and away from home. Food Review 20(2):33-40, 1997.

Pamuk, E.; Makuc, D.; Heck, K.; et al. Socioeconomic Status and Health Chartbook. Health, United States, 1998. Hyattsville, MD: NCHS, 1998.

Wolf, A.M., and Colditz, G.A. Current estimates of the economic cost of obesity in the United States. Obesity Research 6(2):97-106, 1998.

\section{Tobacco Use}

CDC. Guidelines for school health programs to prevent tobacco use and addiction. Morbidity and Mortality Weekly Report 43(RR-2), 1994.

CDC. Smoking-attributable mortality and years of potential life lost-United States, 1984. Morbidity and Mortality Weekly Report 46(20):441-451, 1997.

CDC. Targeting Tobacco Use: The Nation's Leading Cause of Death. Atlanta, GA: HHS, CDC, 1999.

CDC. Youth Risk Behavior Surveillance-United States, 1997. Morbidity and Mortality Weekly Report 47(SS-3):1998.

NCHS. Health, United States, 1999. With health and aging chartbook. Hyattsville, MD: HHS, 1999.

National Cancer Institute. Cigars: Health Effects and Trends. Bethesda, MD: HHS, NIH, 1998.

U.S. Environmental Protection Agency (EPA). Respiratory Health Effects of Passive Smoking: Fact Sheet. EPA Pub. No. EPA-43-F-93-003. Washington, DC: EPA, 1993.
HHS. Tobacco Use Among U.S. Racial/Ethnic Minority Groups-African Americans, American Indians and Alaska Natives, Asian Americans and Pacific Islanders, and Hispanics: A Report of the Surgeon General. Atlanta, GA: HHS, CDC, NCCDPHP, Office on Smoking and Health, 1998.

\section{Substance Abuse}

Center for Substance Abuse Prevention (CSAP), Substance Abuse and Mental Health Services Administration (SAMHSA). Making the Link: Health Care Costs, the Deficit, \& Alcohol, Tobacco, and Other Drugs. NCADI Inventory No. ML007. Rockville, MD: CSAP, 1995.

SAMHSA. Summary of Findings From the 1998 National Household Survey on Drug Abuse. Rockville, MD: HHS, SAMHSA, Office of Applied Studies, 1999.

Harwood, H.; Fountain, D.; and Livermore, G. The Economic Costs of Alcohol and Drug Abuse in the United States, 1992. NIH Pub. No. 98-4327. Rockville, MD: HHS, NIH, 1998.

\section{Responsible Sexual Behavior}

American Social Health Association. Sexually Transmitted Diseases in America: How Many Cases and At What Cost? Menlo Park, CA: Kaiser Family Foundation, 1998.

CDC. CDC guidelines for national human immunodeficiency virus case surveillance, including monitoring for human immunodeficiency virus infection and acquired immunodeficiency syndrome. Morbidity and Mortality Weekly Report 48(RR013), 1999.

CDC. Fact sheet. Youth Risk Behavior Trends. Atlanta, GA: HHS, CDC, NCCDPHP, 1999.

CDC. From Data to Action: CDC's Public Health Surveillance for Women, Infants, and Children. Atlanta, GA: HHS, CDC, NCCDPHP, 1994.

CDC. HIV/AIDS Surveillance Report. Midyear ed. Atlanta, GA: HHS, CDC, 1999.

CDC. PRAMS 1996 Surveillance Report. Atlanta, GA: CDC, NCCDPHP, Division of Reproductive Health, 1999.

CDC. Trends in sexual risk behaviors among high school students-United States, 1991-1997. Morbidity and Mortality Weekly Report 47(36):749-752, 1998. 
CDC. Young people at risk-epidemic shifts further toward young women and minorities. In: CDC Update. Atlanta, GA: HHS, CDC, National Center for HIV, STD, and TB Prevention, 1999.

CDC, Division of STD Prevention. Sexually Transmitted Disease Surveillance, 1998. Atlanta, GA: HHS, CDC, 1999.

NCHS. Healthy People 2000 Review, 1998-99. Hyattsville, MD: HHS, 1999.

Holtgrave, D.R., and Pinkerton, S.D. Updates of cost of illness and quality of life estimates for use in economic evaluations of HIV prevention programs. Journal of Acquired Immune Deficiency Syndromes and Human Retrovirology 16(1):54-62, 1997.

Hoyert, D.L.; Kochanek, K.D.; and Murphy, S.L. Deaths: Final data for 1997. National Vital Statistics Reports 47(19), 1999.

Maynard, R.A., ed. Kids Having Kids; Economic Costs and Social Consequences of Teen Pregnancy. Washington, DC: Urban Institute Press, 1997.

St. Louis, M.E.; Wasserheit, J.N.; and Gayle, H.D. Janus considers the HIV pandemic-harnessing recent advances to enhance AIDS prevention. American Journal of Public Health 87(1):10-12, 1997.

\section{Mental Health}

NCHS. Healthy People 2000 Review, 1998-99. Hyattsville, MD: HHS, 1999.

NIH, Consensus Development Panel on Depression in Late Life. Diagnosis and treatment of depression in late life. Journal of the American Medical Association 268:1018-1024, 1992.

National Institute of Mental Health (NIMH). Depression. Bethesda, MD: HHS, NIH, 1999. <http:// www.nimh.nih.gov/depression/index.htm>.

NIMH. The Invisible Disease-Depression. Bethesda, MD: HHS, NIH, 1999. <http://www.nimh.nih.gov/ publicat/invisible.cfm>.

SAMHSA, Office of Applied Studies. In: Rouse, B.A., ed. SAMHSA Statistics Source Book, 1998. Rockville, MD: HHS, 1998.
SAMHSA. Mental Health: A Report of the Surgeon General. Rockville, MD: HHS, NIH, 1999.

Bromet, E.J. Psychiatric disorders. In: Wallace, R.B., ed. Public Health and Preventive Medicine. 14th ed. Stamford, CT: Appleton \& Lange, 1998, 1037.

Greenberg, P.E.; Stiglin, L.E.; Finkelstein, S.N.; et al. The economic burden of depression in 1990. Journal of Clinical Psychiatry 54:405-418, 1993.

Koenig, H.G., and Blazer, D.G. Mood disorders and suicide. In: Birren, J.E.; Sloane, R.B.; and Cohen, G.D.; eds. Handbook of Mental Health and Aging. 2nd ed. San Diego, CA: Academic Press, 1992, 379-407.

Weissman, M.M., and Klerman, J.K. Depression: Current understanding and changing trends. Annual Review of Public Health 13:319-339, 1992.

\section{Injury and Violence}

NCHS. Healthy People 2000 Review, 1998-99. Hyattsville, MD: HHS, 1999.

National Center for Injury Prevention and Control. Impaired Driving Fact Sheet. Atlanta, GA: HHS, CDC, 1999.

National Highway Traffic Safety Administration. Traffic Safety Facts, 1998. Washington, DC: U.S. Department of Transportation, 1998.

National Safety Council. Accident Facts. Washington, DC: the Council, 1995.

Baker, S.P.; O’Neill, B.; Ginsburg, M.J.; et al. The Injury Fact Book. 2nd ed. New York, NY: Oxford University Press, 1992.

Fox, J.A., and Zawitz, M.W. Homicide Trends in the United States. U.S. Department of Justice, Bureau of Justice Statistics, 1999.

Hoyert, D.L.; Kochanek, K.D.; and Murphy, S.L. Deaths: Final data for 1997. National Vital Statistics Reports 47(19), 1999. 


\section{Environmental Quality}

American Lung Association. Health Costs of Air Pollution. Washington, DC: the Association, 1990.

California Environmental Protection Agency. Health Effects of Exposure to Environmental Tobacco Smoke. Final report. Sacramento, CA: the Agency, Office of Environmental Health Hazard Assessment, 1997.

CDC. Progress toward the elimination of tuberculosisUnited States, 1998. Morbidity and Mortality Weekly Report 48:732-736, 1999.

CDC. State-specific prevalence of cigarette smoking among adults, and children's and adolescents' exposure to environmental tobacco smoke-United States. Morbidity and Mortality Weekly Report 46:1038-1043, 1997.

NCHS. Health, United States, 1999. With health and aging chartbook. Hyattsville, MD: HHS, 1999.

EPA. National Air Quality and Trends Report. Washington, DC: EPA, Office of Air and Radiation, 1997.

EPA. Respiratory Health Effects of Passive Smoking: Lung Cancer and Other Disorders. EPA Pub. No. EPA/ 600/6-90/006F. Washington, DC: EPA, 1992.

World Health Organization (WHO). Fact Sheet 170. Geneva, Switzerland: WHO, 1997.

Mannino, D.M.; Homa, D.M.; Pertowski, C.A.; et al. Surveillance for asthma-United States 1960-1995. In: CDC Surveillance Summaries, April 24, 1998. Morbidity and Mortality Weekly Report 47(SS-1):1-27, 1998.

Weiss, K.B.; Gergen, P.J; and Hodgson, T.A. An economic evaluation of asthma in the United States. New England Journal of Medicine 326:862-866, 1992.

\section{Immunization}

CDC, National Immunization Program, Immunization Services Division, Health Services Research and Evaluation Branch. Unpublished data, 1999.

CDC. National vaccination coverage levels among children aged 19-35 months-United States, 1998. Morbidity and Mortality Weekly Report 48:829-830, 1999.

CDC. Prevention and control of influenza:

Recommendations of the Advisory Committee on Immunization Practices (ACIP). Morbidity and Mortality Weekly Report 48(RR-4), 1999.
CDC. Prevention of pneumococcal disease: Recommendations of the Advisory Committee on Immunization Practices (ACIP). Morbidity and Mortality Weekly Report 46(RR-8), 1997.

CDC. Reasons reported by Medicare beneficiaries for not receiving influenza and pneumococcal vaccinations-United States, 1996. Morbidity and Mortality Weekly Report 48:886-890, 1999.

CDC. Recommended childhood immunization schedule-United States, 1999. Morbidity and Mortality Weekly Report 48:12-16, 1999.

CDC. Ten great public health achievements-United States, 1900-1999. Morbidity and Mortality Weekly Report 48:241-248, 1999.

NCHS. Health, United States, 1999. With health and aging chartbook. Hyattsville, MD: HHS, 1999.

Feiken, D.R.; Schuchat, A.; Kolczak, M.; et al. Mortality from invasive pneumococcal pneumonia in the era of antibiotic resistance, 1995-1997. American Journal of Public Health, in press.

Pamuk, E.; Makuc, D.; Heck, K.; et al. Socioeconomic Status and Health Chartbook. Health, United States, 1998. Hyattsville, MD: NCHS, 1998.

\section{Access to Health Care}

CDC. Health insurance coverage and receipt of preventive health services-United States, 1993. Morbidity and Mortality Weekly Report 44(11):219-225, 1995.

NCHS. Health, United States, 1999. With health and aging chartbook.Hyattsville, MD: HHS, 1999.

U.S. General Accounting Office (GAO). Health Insurance: Coverage Leads to Increased Health Care Access for Children. GAO/HEHS-98-14. Washington, DC: GAO, 1998, 4-20.

The Kaiser Commission on Medicaid and the Uninsured. Uninsured in America: A Chart Book. 2nd ed. Menlo Park, CA: the Commission, 2000. 



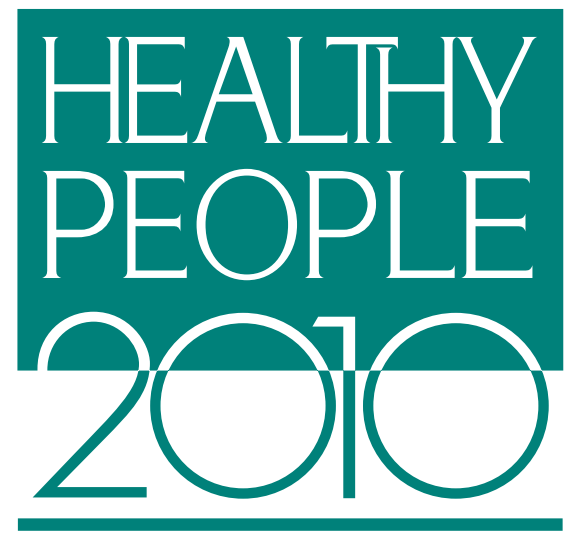

\section{Appendix: Short Titles for Healthy People 2010 Objectives}

\section{Access to Quality Health Services}

Goal: Improve access to comprehensive, high-quality health care services.

\section{Objective Number and Short Title}

\section{Clinical Preventive Care}

1-1 Persons with health insurance

1-2 Health insurance coverage for clinical preventive services

1-3 Counseling about health behaviors

\section{Primary Care}

1-4 Source of ongoing care

1-5 Usual primary care provider

1-6 Difficulties or delays in obtaining needed health care

1-7 Core competencies in health provider training

1-8 Racial and ethnic representation in health professions

1-9 Hospitalization for ambulatory-care-sensitive conditions

\section{Emergency Services}

1-10 Delay or difficulty in getting emergency care

1-11 Rapid prehospital emergency care

1-12 Single toll-free number for poison control centers

1-13 Trauma care systems

1-14 Special needs of children

\section{Long-Term Care and Rehabilitative Services}

1-15 Long-term care services

1-16 Pressure ulcers among nursing home residents

\section{Arthritis, Osteoporosis, and Chronic Back Conditions}

Goal: Prevent illness and disability related to arthritis and other rheumatic conditions, osteoporosis, and chronic back conditions.

\section{Objective Number and Short Title}

\section{Arthritis and Other Rheumatic Conditions}

2-1 Mean number of days without severe pain

2-2 Activity limitations due to arthritis

2-3 Personal care limitations

2-4 Help in coping

2-5 Employment rate

2-6 Racial differences in total knee replacement

2-7 Seeing a health care provider

2-8 Arthritis education

\section{Osteoporosis}

2-9 Cases of osteoporosis

2-10 Hospitalization for vertebral fractures

\section{Chronic Back Conditions}

2-11 Activity limitations due to chronic back conditions 


\section{Cancer}

Goal: Reduce the number of new cancer cases as well as the illness, disability, and death caused by cancer.

\section{Objective Number and Short Title \\ 3-1 Overall cancer deaths \\ 3-2 Lung cancer deaths \\ 3-3 Breast cancer deaths \\ 3-4 Cervical cancer deaths \\ 3-5 Colorectal cancer deaths \\ 3-6 Oropharyngeal cancer deaths \\ 3-7 Prostate cancer deaths \\ 3-8 Melanoma deaths \\ 3-9 Sun exposure and skin cancer \\ 3-10 Provider counseling about cancer prevention \\ 3-11 Pap tests \\ 3-12 Colorectal cancer screening \\ 3-13 Mammograms \\ 3-14 Statewide cancer registries \\ 3-15 Cancer survival}

\section{Chronic Kidney Disease}

Goal: Reduce new cases of chronic kidney disease and its complications, disability, death, and economic costs.

\section{Objective Number and Short Title}

4-1 End-stage renal disease

4-2 Cardiovascular disease deaths in persons with chronic kidney failure

4-3 Counseling for chronic kidney failure care

4-4 Use of arteriovenous fistulas

4-5 Registration for kidney transplantation

4-6 Waiting time for kidney transplantation

4-7 Kidney failure due to diabetes

4-8 Medical therapy for persons with diabetes and proteinuria

\section{Diabetes}

Goal: Through prevention programs, reduce the disease and economic burden of diabetes, and improve the quality of life for all persons who have or are at risk for diabetes.

\section{Objective Number and Short Title}

5-1 Diabetes education

5-2 New cases of diabetes

5-3 Overall cases of diagnosed diabetes
5-4 Diagnosis of diabetes

5-5 Diabetes deaths

5-6 Diabetes-related deaths

5-7 Cardiovascular disease deaths in persons with diabetes

5-8 Gestational diabetes

5-9 Foot ulcers

5-10 Lower extremity amputations

5-11 Annual urinary microalbumin measurement

5-12 Annual glycosylated hemoglobin measurement

5-13 Annual dilated eye examinations

5-14 Annual foot examinations

5-15 Annual dental examinations

5-16 Aspirin therapy

5-17 Self-blood-glucose-monitoring

\section{Disability and Secondary Conditions}

Goal: Promote the health of people with disabilities, prevent secondary conditions, and eliminate disparities between people with and without disabilities in the U.S. population.

\section{Objective Number and Short Title}

6-1 Standard definition of people with disabilities in data sets

6-2 Feelings and depression among children with disabilities

6-3 Feelings and depression interfering with activities among adults with disabilities

6-4 Social participation among adults with disabilities

6-5 Sufficient emotional support among adults with disabilities

6-6 Satisfaction with life among adults with disabilities

6-7 Congregate care of children and adults with disabilities

6-8 Employment parity

6-9 Inclusion of children and youth with disabilities in regular education programs

6-10 Accessibility of health and wellness programs

6-11 Assistive devices and technology

6-12 Environmental barriers affecting participation in activities

6-13 Surveillance and health promotion programs 


\section{Educational and Community-Based Programs}

Goal: Increase the quality, availability, and effectiveness of educational and community-based programs designed to prevent disease and improve health and quality of life.

\section{Objective Number and Short Title}

\section{School Setting}

7-1 High school completion

7-2 School health education

7-3 Health-risk behavior information for college and university students

7-4 School nurse-to-student ratio

\section{Worksite Setting}

7-5 Worksite health promotion programs

7-6 Participation in employer-sponsored health promotion activities

\section{Health Care Setting}

7-7 Patient and family education

7-8 Satisfaction with patient education

7-9 Health care organization sponsorship of community health promotion activities

\section{Community Setting and Select Populations}

7-10 Community health promotion programs

7-11 Culturally appropriate and linguistically competent community health promotion programs

7-12 Older adult participation in community health promotion activities

\section{Environmental Health}

Goal: Promote health for all through a healthy environment.

\section{Objective Number and Short Title}

Outdoor Air Quality

8-1 Harmful air pollutants

8-2 Alternative modes of transportation

8-3 Cleaner alternative fuels

8-4 Airborne toxins

\section{Water Quality}

8-5 Safe drinking water

8-6 Waterborne disease outbreaks

8-7 Water conservation

8-8 Surface water health risks

8-9 Beach closings

8-10 Fish contamination

\section{Toxics and Waste}

8-11 Elevated blood lead levels in children

8-12 Risks posed by hazardous sites

8-13 Pesticide exposures

8-14 Toxic pollutants

8-15 Recycled municipal solid waste

\section{Healthy Homes and Healthy Communities}

8-16 Indoor allergens

8-17 Office building air quality

8-18 Homes tested for radon

8-19 Radon-resistant new home construction

8-20 School policies to protect against environmental hazards

8-21 Disaster preparedness plans and protocols

8-22 Lead-based paint testing

8-23 Substandard housing

\section{Infrastructure and Surveillance}

8-24 Exposure to pesticides

8-25 Exposure to heavy metals and other toxic chemicals

8-26 Information systems used for environmental health

8-27 Monitoring environmentally related diseases

8-28 Local agencies using surveillance data for vector control

\section{Global Environmental Health}

8-29 Global burden of disease

8-30 Water quality in the U.S.-Mexico border region

\section{Family Planning}

Goal: Improve pregnancy planning and spacing and prevent unintended pregnancy.

\section{Objective Number and Short Title}

\section{9-1 Intended pregnancy}

9-2 Birth spacing

9-3 Contraceptive use

9-4 Contraceptive failure

9-5 Emergency contraception

9-6 Male involvement in pregnancy prevention

9-7 Adolescent pregnancy

9-8 Abstinence before age 15 years

9-9 Abstinence among adolescents aged 15 to 17 years

9-10 Pregnancy prevention and sexually transmitted disease (STD) protection

9-11 Pregnancy prevention education

9-12 Problems in becoming pregnant and maintaining a pregnancy

9-13 Insurance coverage for contraceptive supplies and services 


\section{Food Safety}

Goal: Reduce foodborne illnesses.

\section{Objective Number and Short Title \\ 10-1 Foodborne infections \\ 10-2 Outbreaks of foodborne infections \\ 10-3 Antimicrobial resistance of Salmonella species \\ 10-4 Food allergy deaths \\ 10-5 Consumer food safety practices \\ 10-6 Safe food preparation practices in retail establishments \\ 10-7 Organophosphate pesticide exposure}

\section{Health Communication}

Goal: Use communication strategically to improve health.

\section{Objective Number and Short Title}

11-1 Households with Internet access

11-2 Health literacy

11-3 Research and evaluation of communication programs

11-4 Quality of Internet health information sources

11-5 Centers for excellence

11-6 Satisfaction with health care providers' communication skills

\section{Heart Disease and Stroke}

Goal: Improve cardiovascular health and quality of life through the prevention, detection, and treatment of risk factors; early identification and treatment of heart attacks and strokes; and prevention of recurrent cardiovascular events.

\section{Objective Number and Short Title}

\section{Heart Disease}

12-1 Coronary heart disease (CHD) deaths

12-2 Knowledge of symptoms of heart attack and importance of calling 911

12-3 Artery-opening therapy

12-4 Bystander response to cardiac arrest

12-5 Out-of-hospital emergency care

12-6 Heart failure hospitalizations

\section{Stroke}

12-7 Stroke deaths

12-8 Knowledge of early warning symptoms of stroke

\section{Blood Pressure}

12-9 High blood pressure

12-10 High blood pressure control

12-11 Action to help control blood pressure

12-12 Blood pressure monitoring

\section{Cholesterol}

12-13 Mean total blood cholesterol levels

12-14 High blood cholesterol levels

12-15 Blood cholesterol screening

12-16 LDL-cholesterol level in CHD patients

13. HIV

Goal: Prevent HIV infection and its related illness and death.

\section{Objective Number and Short Title}

13-1 New AIDS cases

13-2 AIDS among men who have sex with men

13-3 AIDS among persons who inject drugs

13-4 AIDS among men who have sex with men and who inject drugs

13-5 New HIV cases

13-6 Condom use

13-7 Knowledge of serostatus

13-8 HIV counseling and education for persons in substance abuse treatment

13-9 HIV/AIDS, STD, and TB education in State prisons

13-10 HIV counseling and testing in State prisons

13-11 HIV testing in TB patients

13-12 Screening for STDs and immunization for hepatitis B

13-13 Treatment according to guidelines

13-14 HIV-infection deaths

13-15 Interval between HIV infection and AIDS diagnosis

13-16 Interval between AIDS diagnosis and death from AIDS

13-17 Perinatally acquired HIV infection

\section{Immunization and Infectious} Diseases

Goal: Prevent disease, disability, and death from infectious diseases, including vaccine-preventable diseases.

\section{Objective Number and Short Title}

\begin{tabular}{ll}
\multicolumn{2}{l}{ Diseases Preventable Through Universal Vaccination } \\
$14-1 \quad$ Vaccine-preventable diseases \\
$14-2 \quad$ Hepatitis B in infants and young children \\
$14-3 \quad$ Hepatitis B in adults and high-risk groups \\
$14-4 \quad$ Bacterial meningitis in young children \\
$14-5 \quad$ Invasive pneumococcal infections
\end{tabular}


Diseases Preventable Through Targeted Vaccination 14-6 Hepatitis A

14-7 Meningococcal disease

14-8 Lyme disease

Infectious Diseases and Emerging Antimicrobial Resistance

14-9 Hepatitis C

14-10 Identification of persons with chronic hepatitis $\mathrm{C}$

14-11 Tuberculosis

14-12 Curative therapy for tuberculosis

14-13 Treatment for high-risk persons with latent tuberculosis infection

14-14 Timely laboratory confirmation of tuberculosis cases

14-15 Prevention services for international travelers

14-16 Invasive early onset group B streptococcal disease

14-17 Peptic ulcer hospitalizations

14-18 Antibiotics prescribed for ear infections

14-19 Antibiotics prescribed for common cold

14-20 Hospital-acquired infections

14-21 Antimicrobial use in intensive care units

Vaccination Coverage and Strategies

14-22 Universally recommended vaccination of children aged 19 to 35 months

14-23 Vaccination coverage for children in day care, kindergarten, and first grade

14-24 Fully immunized young children and adolescents

14-25 Providers who measure childhood vaccination coverage levels

14-26 Children participating in population-based immunization registries

14-27 Vaccination coverage among adolescents

14-28 Hepatitis B vaccination among high-risk groups

14-29 Influenza and pneumococcal vaccination of high-risk adults

Vaccine Safety

14-30 Adverse events from vaccinations

14-31 Active surveillance for vaccine safety
15. Injury and Violence Prevention

Goal: Reduce injuries, disabilities, and deaths due to unintentional injuries and violence.

\section{Objective Number and Short Title}

\section{Injury Prevention}

15-1 Nonfatal head injuries

15-2 Nonfatal spinal cord injuries

15-3 Firearm-related deaths

15-4 Proper firearm storage in homes

15-5 Nonfatal firearm-related injuries

15-6 Child fatality review

15-7 Nonfatal poisonings

15-8 Deaths from poisoning

15-9 Deaths from suffocation

15-10 Emergency department surveillance systems

15-11 Hospital discharge surveillance systems

15-12 Emergency department visits

Unintentional Injury Prevention

15-13 Deaths from unintentional injuries

15-14 Nonfatal unintentional injuries

15-15 Deaths from motor vehicle crashes

15-16 Pedestrian deaths

15-17 Nonfatal motor vehicle injuries

15-18 Nonfatal pedestrian injuries

15-19 Safety belts

15-20 Child restraints

15-21 Motorcycle helmet use

15-22 Graduated driver licensing

15-23 Bicycle helmet use

15-24 Bicycle helmet laws

15-25 Residential fire deaths

15-26 Functioning smoke alarms in residences

15-27 Deaths from falls

15-28 Hip fractures

15-29 Drownings

15-30 Dog bite injuries

15-31 Injury protection in school sports

\section{Violence and Abuse Prevention}

15-32 Homicides

15-33 Maltreatment and maltreatment fatalities of children

15-34 Physical assault by intimate partners

15-35 Rape or attempted rape

15-36 Sexual assault other than rape

15-37 Physical assaults

15-38 Physical fighting among adolescents

15-39 Weapon carrying by adolescents on school property 


\section{Maternal, Infant, and Child Health}

Goal: Improve the health and well-being of women, infants, children, and families.

\section{Objective Number and Short Title}

\section{Fetal, Infant, Child, and Adolescent Deaths \\ 16-1 Fetal and infant deaths \\ 16-2 Child deaths \\ 16-3 Adolescent and young adult deaths}

\section{Maternal Deaths and IIInesses \\ 16-4 Maternal deaths \\ 16-5 Maternal illness and complications due to pregnancy}

\section{Prenatal Care}

16-6 Prenatal care

16-7 Childbirth classes

\section{Obstetrical Care}

16-8 Very low birth weight infants born at level III hospitals

16-9 Cesarean births

\section{Risk Factors}

16-10 Low birth weight and very low birth weight

16-11 Preterm births

16-12 Weight gain during pregnancy

16-13 Infants put to sleep on their backs

Developmental Disabilities and Neural Tube Defects 16-14 Developmental disabilities

16-15 Spina bifida and other neural tube defects

16-16 Optimum folic acid levels

\section{Prenatal Substance Exposure}

16-17 Prenatal substance exposure

16-18 Fetal alcohol syndrome

\section{Breastfeeding, Newborn Screening, and Service Systems}

16-19 Breastfeeding

16-20 Newborn bloodspot screening

16-21 Sepsis among children with sickle cell disease

16-22 Medical homes for children with special health care needs

16-23 Service systems for children with special health care needs

\section{Medical Product Safety}

Goal: Ensure the safe and effective use of medical products.

\section{Objective Number and Short Title}

17-1 Monitoring of adverse medical events

17-2 Linked, automated information systems

17-3 Provider review of medications taken by patients

17-4 Receipt of useful information about prescriptions from pharmacies

17-5 Receipt of oral counseling about medications from prescribers and dispensers

17-6 Blood donations

\section{Mental Health and Mental Illness}

Goal: Improve mental health and ensure access to appropriate, quality mental health services.

\section{Objective Number and Short Title}

\section{Mental Health Status Improvement}

18-1 Suicide

18-2 Adolescent suicide attempts

18-3 Serious mental illness (SMI) among homeless adults

18-4 Employment of persons with SMI

18-5 Eating disorder relapses

\section{Treatment Expansion}

18-6 Primary care screening and assessment

18-7 Treatment for children with mental health problems

18-8 Juvenile justice facility screening

18-9 Treatment for adults with mental disorders

18-10 Treatment for co-occurring disorders

18-11 Adult jail diversion programs

\section{State Activities}

18-12 State tracking of consumer satisfaction

18-13 State plans addressing cultural competence

18-14 State plans addressing elderly persons 


\section{Nutrition and Overweight}

Goal: Promote health and reduce chronic disease associated with diet and weight.

\section{Objective Number and Short Title}

\section{Weight Status and Growth}

19-1 Healthy weight in adults

19-2 Obesity in adults

19-3 Overweight or obesity in children and adolescents

19-4 Growth retardation in children

\section{Food and Nutrient Consumption}

19-5 Fruit intake

19-6 Vegetable intake

19-7 Grain product intake

19-8 Saturated fat intake

19-9 Total fat intake

19-10 Sodium intake

19-11 Calcium intake

\section{Iron Deficiency and Anemia}

19-12 Iron deficiency in young children and in females of childbearing age

19-13 Anemia in low-income pregnant females

19-14 Iron deficiency in pregnant females

Schools, Worksites, and Nutrition Counseling

19-15 Meals and snacks at school

19-16 Worksite promotion of nutrition education and weight management

19-17 Nutrition counseling for medical conditions

\section{Food Security}

19-18 Food security

\section{Occupational Safety and Health}

Goal: Promote the health and safety of people at work through prevention and early intervention.

\section{Objective Number and Short Title}

20-1 Work-related injury deaths

20-2 Work-related injuries

20-3 Overexertion or repetitive motion

20-4 Pneumoconiosis deaths

20-5 Work-related homicides

20-6 Work-related assaults

20-7 Elevated blood lead levels from work exposure

20-8 Occupational skin diseases or disorders

20-9 Worksite stress reduction programs

20-10 Needlestick injuries

20-11 Work-related, noise-induced hearing loss

\section{Oral Health}

Goal: Prevent and control oral and craniofacial diseases, conditions, and injuries and improve access to related services.

\section{Objective Number and Short Title}

21-1 Dental caries experience

21-2 Untreated dental decay

21-3 No permanent tooth loss

21-4 Complete tooth loss

21-5 Periodontal diseases

21-6 Early detection of oral and pharyngeal cancers

21-7 Annual examinations for oral and pharyngeal cancers

21-8 Dental sealants

21-9 Community water fluoridation

21-10 Use of oral health care system

21-11 Use of oral health care system by residents in long-term care facilities

21-12 Dental services for low-income children

21-13 School-based health centers with oral health component

21-14 Health centers with oral health service components

21-15 Referral for cleft lip or palate

21-16 Oral and craniofacial State-based surveillance system

21-17 Tribal, State, and local dental programs

\section{Physical Fitness and Activity}

Goal: Improve health, fitness, and quality of life through daily physical activity.

\section{Objective Number and Short Title}

\section{Physical Activity in Adults}

22-1 No leisure-time physical activity

22-2 Moderate physical activity

22-3 Vigorous physical activity

\section{Muscular Strength/Endurance and Flexibility}

22-4 Muscular strength and endurance

22-5 Flexibility

Physical Activity in Children and Adolescents

22-6 Moderate physical activity in adolescents

22-7 Vigorous physical activity in adolescents

22-8 Physical education requirement in schools

22-9 Daily physical education in schools

22-10 Physical activity in physical education class

22-11 Television viewing

Access

22-12 School physical activity facilities

22-13 Worksite physical activity and fitness

22-14 Community walking

22-15 Community bicycling 


\section{Public Health Infrastructure}

Goal: Ensure that Federal, Tribal, State, and local health agencies have the infrastructure to provide essential public health services effectively.

\section{Objective Number and Short Title}

\section{Data and Information Systems}

23-1 Public health employee access to the Internet

23-2 Public access to information and surveillance data

23-3 Use of geocoding in health data systems

23-4 Data for all population groups

23-5 Data for Leading Health Indicators, Health Status Indicators, and Priority Data Needs at Tribal, State, and local levels

23-6 National tracking of Healthy People 2010 objectives

23-7 Timely release of data on objectives

\section{Workforce}

23-8 Competencies for public health workers

23-9 Training in essential public health services

23-10 Continuing education and training by public health agencies

\section{Public Health Organizations}

23-11 Performance standards for essential public health services

23-12 Health improvement plans

23-13 Access to public health laboratory services

23-14 Access to epidemiology services

23-15 Model statutes related to essential public health services

\section{Resources}

23-16 Data on public health expenditures

Prevention Research

23-17 Population-based prevention research

\section{Respiratory Diseases}

Goal: Promote respiratory health through better prevention, detection, treatment, and education efforts.

\section{Objective Number and Short Title}

\section{Asthma}

24-1 Deaths from asthma

24-2 Hospitalizations for asthma

24-3 Hospital emergency department visits for asthma

24-4 Activity limitations

24-5 School or work days lost

24-6 Patient education

24-7 Appropriate asthma care

24-8 Surveillance systems

Chronic Obstructive Pulmonary Disease (COPD)

24-9 Activity limitations due to chronic lung and breathing problems

24-10 Deaths from COPD

\section{Obstructive Sleep Apnea (OSA)}

24-11 Medical evaluation and followup

24-12 Vehicular crashes related to excessive sleepiness

\section{Sexually Transmitted Diseases}

Goal: Promote responsible sexual behaviors, strengthen community capacity, and increase access to quality services to prevent sexually transmitted diseases (STDs) and their complications.

\section{Objective Number and Short Title}

\section{Bacterial STD IIIness and Disability \\ 25-1 Chlamydia \\ 25-2 Gonorrhea \\ 25-3 Primary and secondary syphilis}

Viral STD IIIness and Disability

25-4 Genital herpes

25-5 Human papillomavirus infection

STD Complications Affecting Females

25-6 Pelvic inflammatory disease (PID)

25-7 Fertility problems

25-8 Heterosexually transmitted HIV infection in women 
STD Complications Affecting the Fetus and Newborn

25-9 Congenital syphilis

25-10 Neonatal STDs

\section{Personal Behaviors}

25-11 Responsible adolescent sexual behavior

25-12 Responsible sexual behavior messages on television

\section{Community Protection Infrastructure}

25-13 Hepatitis B vaccine services in STD clinics

25-14 Screening in youth detention facilities and jails

25-15 Contracts to treat nonplan partners of STD patients

\section{Personal Health Services}

25-16 Annual screening for genital chlamydia

25-17 Screening of pregnant women

25-18 Compliance with recognized STD treatment standards

25-19 Provider referral services for sex partners

\section{Substance Abuse}

Goal: Reduce substance abuse to protect the health, safety, and quality of life for all, especially children.

\section{Objective Number and Short Title}

\section{Adverse Consequences of Substance Use and} Abuse

26-1 Motor vehicle crash deaths and injuries

26-2 Cirrhosis deaths

26-3 Drug-induced deaths

26-4 Drug-related hospital emergency department visits

26-5 Alcohol-related hospital emergency department visits

26-6 Adolescents riding with a driver who has been drinking

26-7 Alcohol- and drug-related violence

26-8 Lost productivity

\section{Substance Use and Abuse}

26-9 Substance-free youth

26-10 Adolescent and adult use of illicit substances

26-11 Binge drinking

26-12 Average annual alcohol consumption

26-13 Low-risk drinking among adults

26-14 Steroid use among adolescents

26-15 Inhalant use among adolescents
Risk of Substance Use and Abuse

26-16 Peer disapproval of substance abuse

26-17 Perception of risk associated with substance abuse

Treatment for Substance Abuse

26-18 Treatment gap for illicit drugs

26-19 Treatment in correctional institutions

26-20 Treatment for injection drug use

26-21 Treatment gap for problem alcohol use

\section{State and Local Efforts}

26-22 Hospital emergency department referrals

26-23 Community partnerships and coalitions

26-24 Administrative license revocation laws

26-25 Blood alcohol concentration (BAC) levels for motor vehicle drivers

\section{Tobacco Use}

Goal: Reduce illness, disability, and death related to tobacco use and exposure to secondhand smoke.

\section{Objective Number and Short Title}

\section{Tobacco Use in Population Groups}

27-1 Adult tobacco use

27-2 Adolescent tobacco use

27-3 Initiation of tobacco use

27-4 Age at first tobacco use

\section{Cessation and Treatment}

27-5 Smoking cessation by adults

27-6 Smoking cessation during pregnancy

27-7 Smoking cessation by adolescents

27-8 Insurance coverage of cessation treatment

\section{Exposure to Secondhand Smoke}

27-9 Exposure to tobacco smoke at home among children

27-10 Exposure to environmental tobacco smoke

27-11 Smoke-free and tobacco-free schools

27-12 Worksite smoking policies

27-13 Smoke-free indoor air laws

\section{Social and Environmental Changes}

27-14 Enforcement of illegal tobacco sales to minors laws

27-15 Retail license suspension for sales to minors

27-16 Tobacco advertising and promotion targeting adolescents and young adults

27-17 Adolescent disapproval of smoking

27-18 Tobacco control programs

27-19 Preemptive tobacco control laws

27-20 Tobacco product regulation

27-21 Tobacco tax 


\section{Vision and Hearing}

Goal: Improve the visual and hearing health of the Nation through prevention, early detection, treatment, and rehabilitation.

\section{Objective Number and Short Title}

\section{Vision}

28-1 Dilated eye examinations

28-2 Vision screening for children

28-3 Impairment due to refractive errors

28-4 Impairment in children and adolescents

28-5 Impairment due to diabetic retinopathy

28-6 Impairment due to glaucoma

28-7 Impairment due to cataract

28-8 Occupational eye injury

28-9 Protective eyewear

28-10 Vision rehabilitation services and devices

\section{Hearing}

28-11 Newborn hearing screening, evaluation, and intervention

28-12 Otitis media

28-13 Rehabilitation for hearing impairment

28-14 Hearing examination

28-15 Evaluation and treatment referrals

28-16 Hearing protection

28-17 Noise-induced hearing loss in children

28-18 Noise-induced hearing loss in adults 


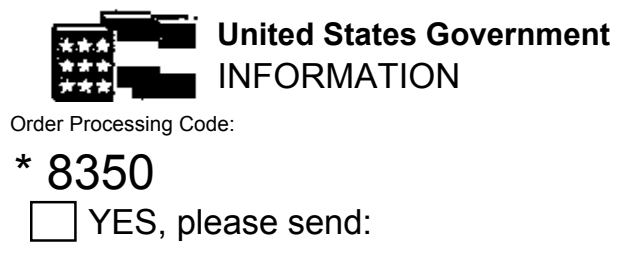

Credit card orders are welcome!

Fax your orders (202) 512-2250

Phone your orders (202) 512-1800

Healthy People 2010 (second edition; Volume I, 608 pages; Volume II, 664 pages) Presents the 467 national health objectives that cover 28 focus areas. Includes data on population groups. Volume I includes black and white version of Understanding and Improving Health (see below). Two-volume set: \$70 (\$87.50 foreign), S/N 017-001-00547-9.

Healthy People 2010, Understanding and Improving Health (second edition; 76 pages; four-color version) - Explains the history of the Healthy People initiative, the model on which Healthy People 2010 is based, how to use Healthy People 2010 as a systematic approach to health improvement, and the Leading Health Indicators. $\$ 10$ (\$12.50 foreign), S/N 017-001-00550-9.

Tracking Healthy People 2010 (996 pages) - A statistical compendium that provides information on measuring the objectives, technical notes, and operational definitions. \$66 (\$82.50 foreign), S/N 017-001-00548-7.

Healthy People 2010 CD-ROM - Contains electronic files of Understanding and Improving Health, Healthy People 2010, and Tracking Healthy People 2010 (Microsoft Word, HTML, PDF, and RTF). \$19 (\$23.75 foreign), S/N 017-001-00549-5.

The total cost of my order is $\$$

Price includes regular shipping \& handling and is subject to change.

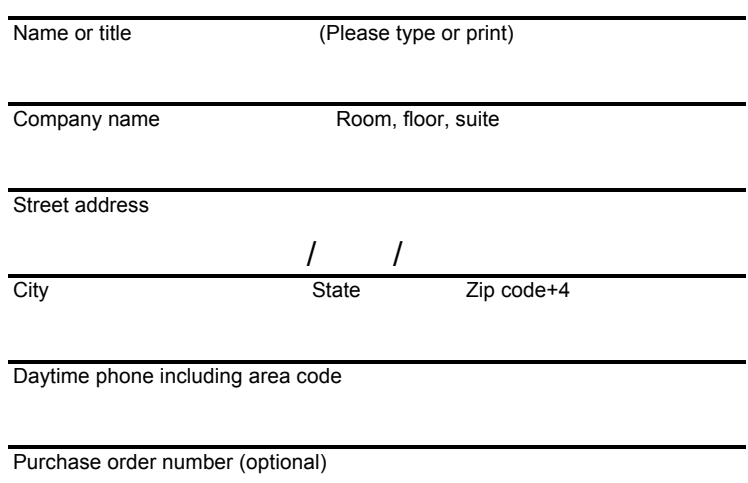

Check method of payment:

$\square$ Check payable to: Superintendent of Documents
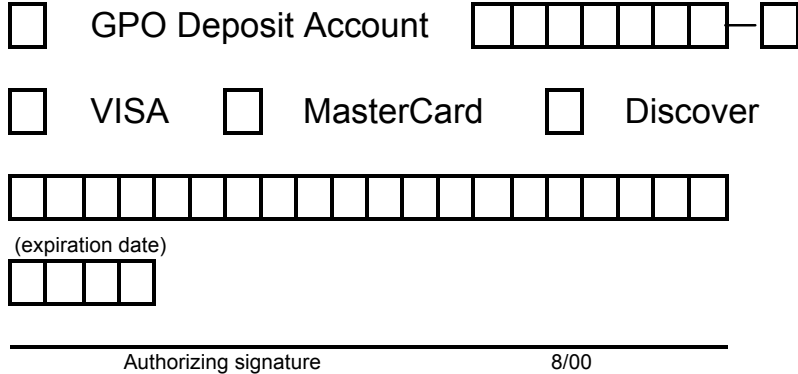

Mail to: Superintendent of Documents, PO Box 371954, Pittsburgh PA 15250-7954 Important: Please include this completed order form with your remittance.

Thank you for your order! 


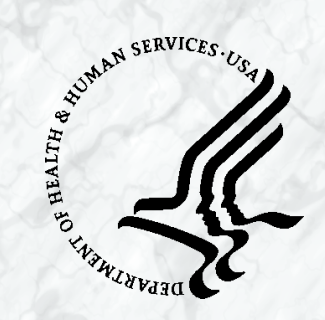

U.S. DEPARTMENT OF HEALTH AND HUMAN SERVICES 